\title{
Embolization in Trauma: Review of Basic Principles and Techniques
}

\author{
Jorge E. Lopera, MD, FSIR ${ }^{1}$ \\ ${ }^{1}$ Department of Radiology, UT Health San Antonio, \\ San Antonio, Texas
}

Semin Intervent Radiol 2021;38:18-33
Address for correspondence Jorge E. Lopera, MD, FSIR, Department of Radiology UT Health San Antonio, 7703 Floyd Curl Drive, San Antonio, TX 78229 (e-mail: Lopera@uthscsa.edu).

\section{Abstract \\ Keywords \\ - embolization \\ - trauma \\ - transcatheter embolization \\ - interventional radiology}

Trauma is the leading cause of death in patients younger than 45 years. Over the last decade, there has been a progressive paradigm shift toward a nonoperative management of many blunt and penetrating injuries, placing interventional radiology in the forefront in this critical field. Transcatheter embolization is an established technique that plays a significant role in the modern treatment of traumatic injuries of the extremities, pelvis, and solid organs. The purpose of this article is to review the updated principles and techniques used in transcatheter embolization in trauma.
Embolization is the intentional and controlled occlusion of vessels to stop hemorrhage in traumatic injuries of solid abdominal organs, extremities, and pelvis. Embolization provides an expedited and minimally invasive control of bleeding with less disruption of normal tissues than surgery, and plays a critical role in the nonoperative management (NOM) of many traumatic injuries, resulting in a decreased need for blood transfusion and improved survival. ${ }^{1,2}$

Managing traumatic injuries requires a multidisciplinary approach with interventional radiology (IR) as an integral part of the team. The creation of rapid response teams led by trauma surgery and IR, and the use of hybrid operative rooms (HORs) where available, has revolutionized the treatment of many traumatic injuries. ${ }^{3,4}$ Many patients who were treated with surgery in the past can now be treated with expedited embolization even in hemodynamically unstable situations. Also, embolization can be a lifesaving procedure for those patients who are having uncontrollable bleeding during surgery. In a HOR, immediate control of hemorrhage can be achieved without the need to transfer the patients between services. ${ }^{3}$ Bleeding control before severe coagulopathy and hypothermia is critical to improve survival. ${ }^{5}$ In some places where embolization techniques are not readily available, resuscitative endovascular balloon occlusion of the aorta (REBOA) catheters have been used successfully to stabilize the patients while definitive options of bleeding control, including embolization, are available. ${ }^{6}$ Early embolization has been associated with decreased mortality in complex pelvic fractures. ${ }^{7,8}$ The Society or Interventional Radiology and the American College of Surgery Committee had recently recommended that the IR team should be ready to intervene within 60 minutes from the time a joint decision is made to proceed with angiography. ${ }^{9}$ The expedited and safe control of hemorrhage with embolization requires a comprehensive understanding of the basic and advanced embolization techniques and materials. ${ }^{10}$

\section{General Principles of Embolization in Trauma}

A rapid response by IR in trauma is essential. A multidisciplinary team with trauma surgery, anesthesia, orthopaedics, vascular surgery, urology, and IR among other services is critical to improve outcomes. Significant differences in the triage of patients exist between centers with HOR and those with IR in a separate area. Close coordination between services is very important to prevent unnecessary delays.

A rapid review of computed tomographic (CT) scan images if available is very important. Areas of active extravasation, vessel transection, pseudoaneurysms (PSAs), arteriovenous fistulas (AVFs), hematomas, etc., are quickly identified and used to guide superselective catheterization of areas of suspected injuries.
Issue Theme Seminars in IR Trauma; Guest Editors, Patrick D. Sutphin, MD. PhD and Sanjeeva Kalva, MD (c) 2021. Thieme. All rights reserved. Thieme Medical Publishers, Inc., 333 Seventh Avenue, 18th Floor, New York, NY 10001, USA
DOI https://doi.org/ 10.1055/s-0041-1724015. ISSN 0739-9529. 

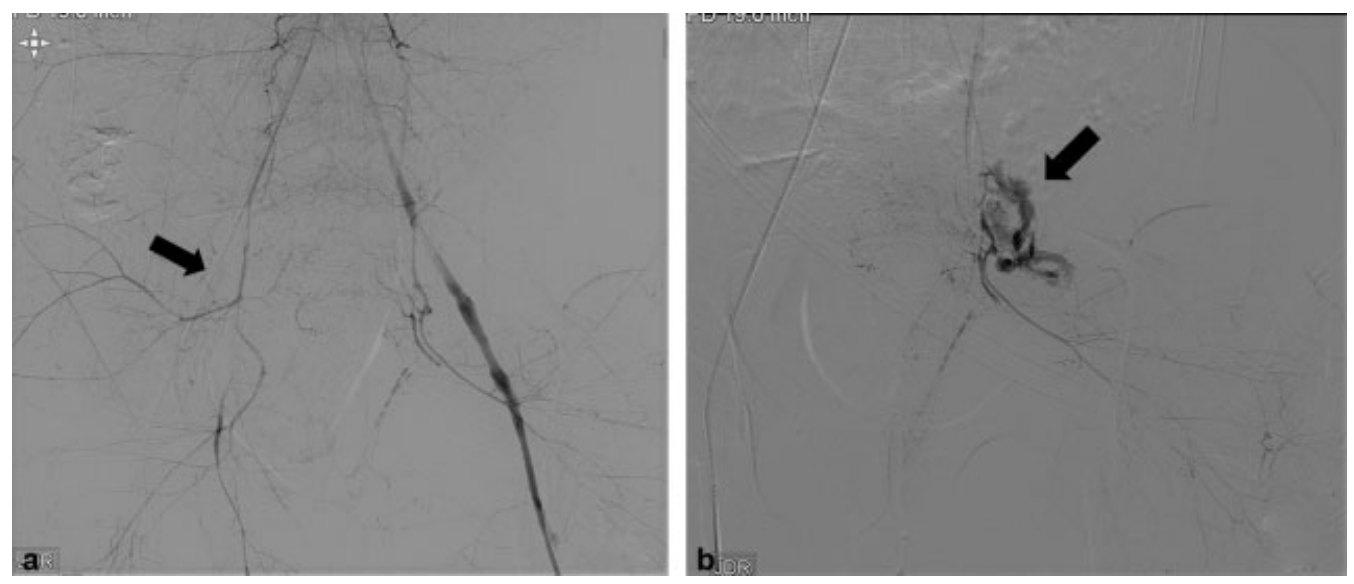

Fig. 1 (a) Digital subtraction angiography in a hypotensive patient with pelvic fracture shows that the right arterial access sheath is occlusive (arrow). Diffuse areas of spasm are seen without clear contrast areas of arterial injury. (b) Superselective catheterization of the left hypogastric artery demonstrates active extravasation near the origin of the inferior gluteal artery (arrow) that was later embolized with coils.

The degree of solid-organ injury, amount of hemoperitoneum or retroperitoneal hematoma, type and severity of pelvic and extremity fractures if present, and an assessment of other associated critical injuries such a brain injuries, in conjunction with the hemodynamic condition of the patient, are critical information used to guide surgical or NOM management.

A Foley catheter is necessary in most unstable patients and essential in patients with pelvic fractures, as the distended bladder with contrast may interfere with adequate visualization of potential bleeding areas.

In most emergency situations, laboratory tests to asses kidney function are not relevant, as controlling the bleeding is the main priority. In semi-urgent situations, the coagulation parameters are quickly corrected and adequate hydration is given to prevent contrast-induced nephrotoxicity.

\section{Arterial Access}

Arterial access is usually obtained using a common femoral approach on the side opposite to pelvic or lower extremity injuries. In a patient with poor or nonpalpable pulses, ultrasound guidance is used to obtain arterial access. For most procedures, a 5-Fr vascular sheath is used. In patients who are very hypotensive, the sheath can be occlusive at the femoral and iliac vessels, and expedited embolization with rapid removal of the sheath is important to prevent vessel thromboSis (-Fig. 1).

A radial access can also be used with the advantages of facilitating bilateral catheterization of the hypogastric arteries in pelvic trauma. Radial access is especially useful in those patients who have a pelvic binder in place, as the angiography with the radial access does not require removal or reposition of the binder. Kidney and liver injuries can also be embolized with a radial access. In patients with a very tortuous splenic artery, even the $150-\mathrm{cm}$ microcatheters may not reach distally enough for superselective embolization. One ideal use of radial artery access is in patient with significant hematuria after a nephrostomy tube, where this approach in the prone position facilitates repeating the angiogram after removing the tube over a wire, without changing the patient position (-Fig. 2).

Manual compression at the common femoral artery access is performed after the procedure. Closure devices can be used in trauma and are very useful to achieve femoral hemostasis in obese, combative, and coagulopathic patients. In patients with contaminated injuries, the risk of infection of the closure device is a major concern.
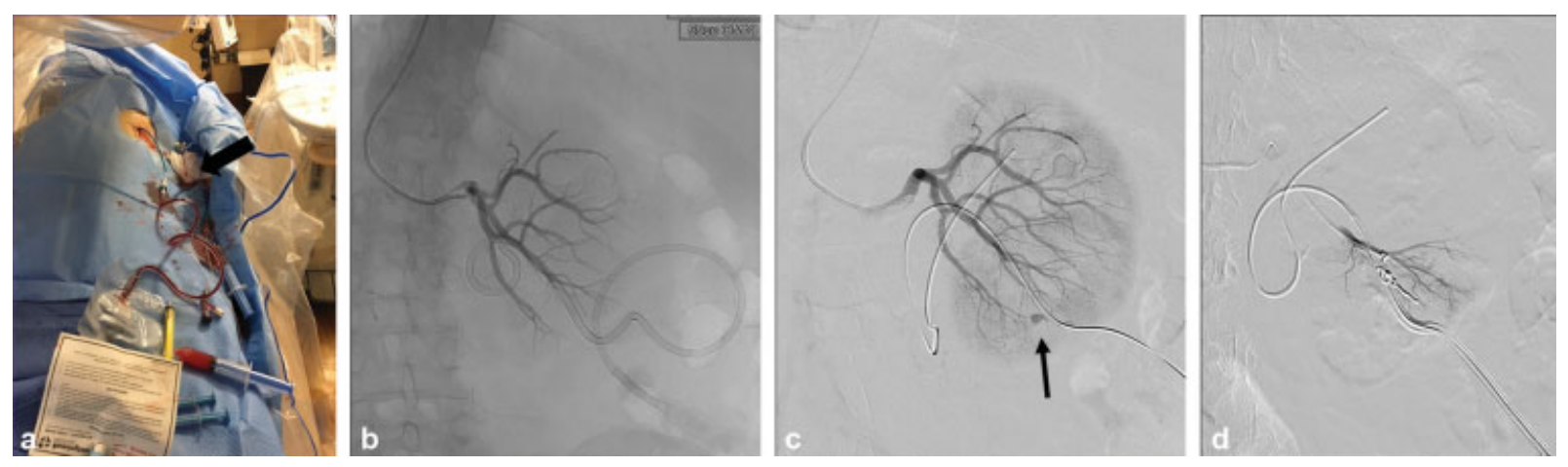

Fig. 2 Patient with significant hematuria after a percutaneous nephrostomy tube (PCN) placement. (a) Photograph shows patient in the prone position with a left radial access (arrow) and the flank area draped allowing performance of the whole procedure in a one position. (b) Initial left renal angiograms show no evidence of bleeding. (c) Repeat angiography with the catheter removed over a guidewire shows a pseudoaneurysm (PSA; arrow). (d) Digital subtraction angiography after superselective embolization with coils shows exclusion of PSA. The PCN tube was replaced with a new one. 
In patients who are severely coagulopathic, unstable, and with the potential need for repeat angiography, the arterial sheath can be left in placed sutured to the skin and connected to a continuous saline flush. If a flush with heparinized saline is used, a controlled slow infusion with a pump is very important to prevent accidental administration of large volumes of saline with heparin.

In some cases when a REBOA catheter is already in place to stabilize the patient, contralateral femoral access is usually performed with angiograms after deflation of the balloon.

\section{Table Setup}

Ideally a separate table is set up with bowls for saline and contrast material, and dextrose 5\% (D5\%) if N-butyl cyanoacrylate (glue) is used ( - Fig. 3 ). In our institution, a customized syringe package with multiple Medallion syringes (Merit Medical, South Jordan, UT) of 1, 3, 5, and $10 \mathrm{~mL}$ of different colors is used. Red syringes are used for glue and particle/Gelfoam embolization, with other colored syringes marked as "contrast" and "saline." The syringes used for particle injection should not be used to inject contrast for postembolization angiograms, as many of the particles will lodge in the hub of a microcatheter and get stuck in the walls of the syringes. When using glue, the syringes should be new and not previously used for saline or contrast material injections to prevent precipitation of the agent.

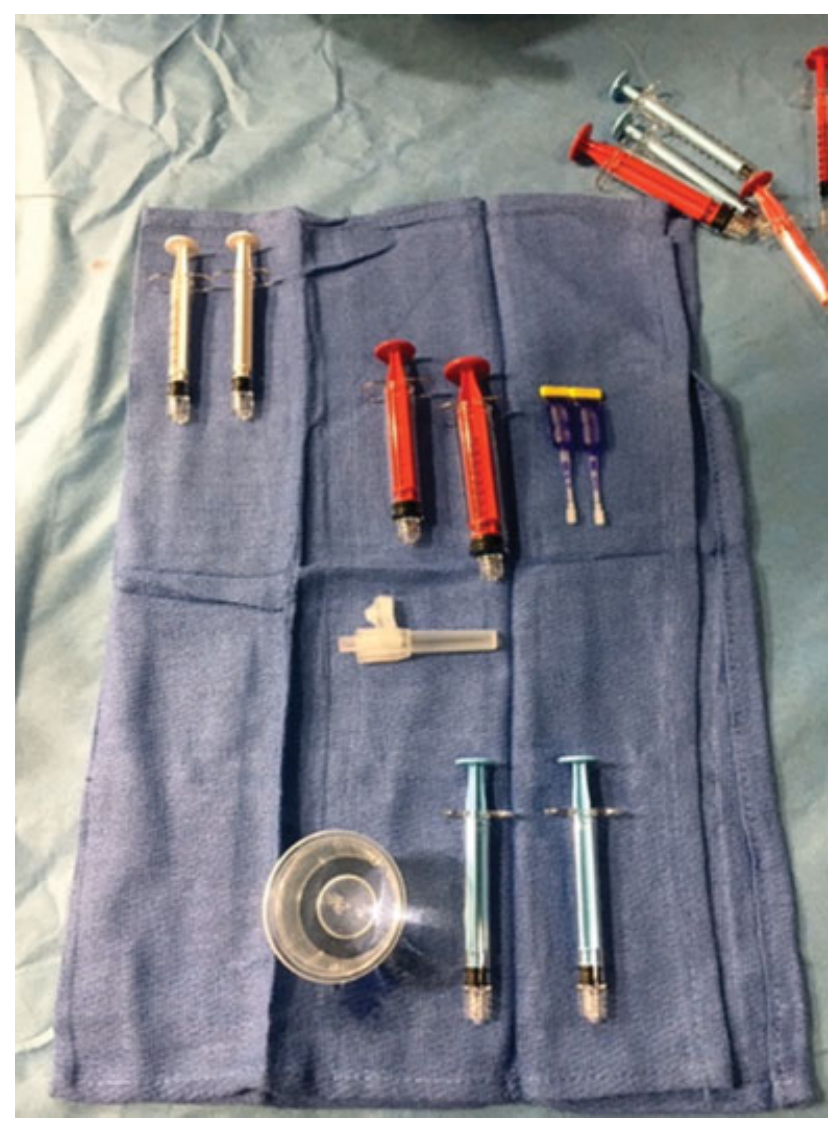

Fig. 3 Photograph of a table setup for glue embolization showing a bowl with D5\%, different color syringes, Histoacryl, and an 18-G needle used to draw the lipiodol.
To save critical time, the table is set up by the operating room (OR) team in the HOR at our institution while the IR team is getting mobilized to arrive to the hospital. Adequate labeling of the bowls for saline and contrast material, with proper communication between the teams, is very important to avoid accidents. For example, the OR team initially place lidocaine in a small cup on the table, while the same type of cup is used for contrast material in the IR area. Injecting the wrong agent can easily happen in an emergency, unless a uniform table setup is coordinated between different teams.

\section{Selective versus Nonselective Catheterization and Embolization}

In most cases, selective catheterization is performed depending on clinical presentation and the suspected areas of arterial injuries seen on the CT scan.

For an acutely injured patient who is taken straight to the HOR or angiography room without additional imaging, nonselective aortograms are performed first to rule out aortic injuries and to quickly identify potential sites of bleeding from lumbar, intercostal, and other branches of the aorta. Angiographic findings suggestive of vascular injury include contrast extravasation, arterial occlusion, AVF, and PSA.

Vasoconstriction in hypotensive patients may prevent areas of arterial injuries to be readily visualized and selective catheterization is required. Selective catheterization of the hypogastric arteries is always recommended in pelvic injuries ( $\mathbf{- F i g . 1}$ ). Also, selective catheterization of areas with a high suspicious of injuries based on the clinical presentation, radiographs, and/or CT scan findings is recommended. In high-grade splenic, liver, and pelvic injuries, superselective catheterization with angiograms in multiple projections is recommended.

Vessels in the young trauma population tend to spasm frequently. In an unstable patient with multiple areas of contrast extravasation where there is an urgent need for an expedited treatment, nonselective embolization may be required, for example, in multiple arterial injuries of the pelvis or the liver. In these cases, a temporary agent such as gelatin sponge (Gelfoam; Pfizer Corp, New York, NY; Surgifoam, Ethicon, Inc., Somerville, NJ) is used.

If the trauma patient is relatively stable, superselective embolization is always recommended to preserve organ tissue, avoid tissue ischemia or necrosis, and decrease the changes of distal recanalization and rebleeding.

Anatomical areas with extensive collateral supply such as the pelvis, liver, upper gastrointestinal tract, and pancreas can tolerate relatively large areas of embolization. Embolization of terminal branches such as the kidney and spleen arteries usually results in distal infarction.

Distal reconstitution of embolized branches can result in recurrent bleeding; this is a frequent problem in injuries of the muscular branches of the extremities, the intercostal and lumbar branches, and organs with extensive collateral circulation. Rebleeding can be prevented using proximal and distal embolization with the "sandwich technique." If the vessel is partially transected, the lesion is carefully crossed distally and coils placed first distal and then proximal to the lesion (-Fig. 4). If the vessel is completely transected, only 

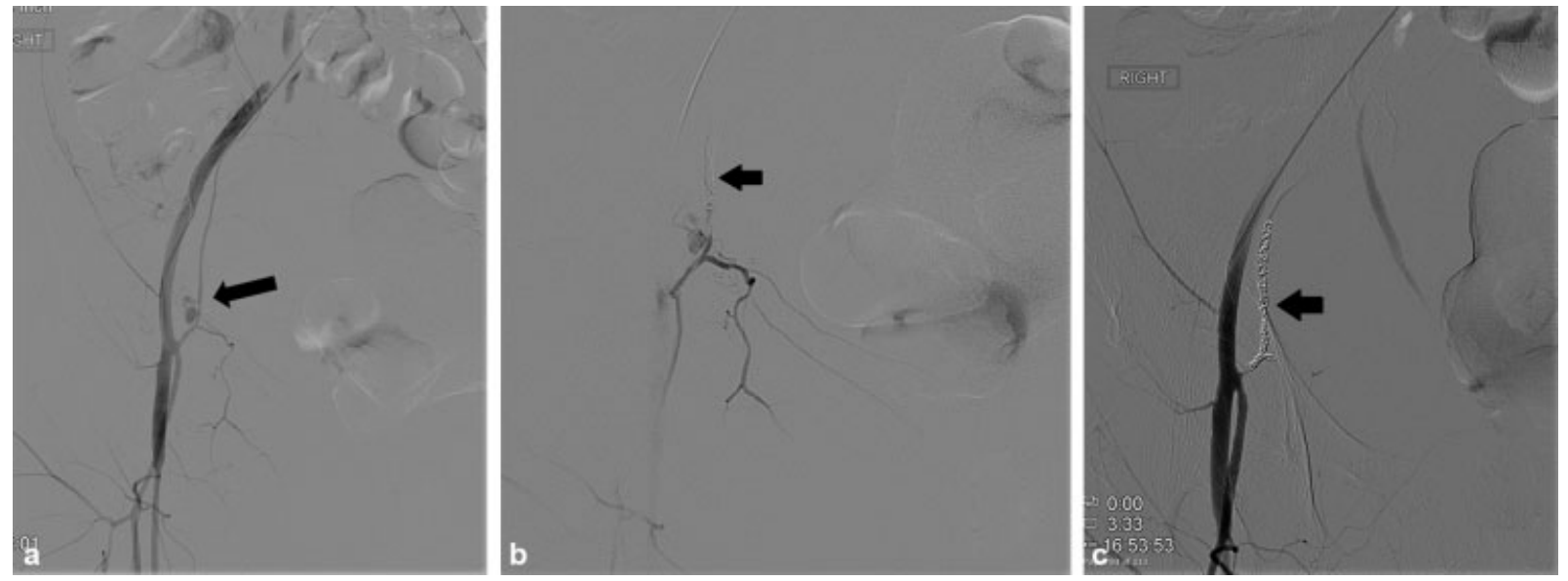

Fig. 4 (a) Digital subtraction angiography shows a pseudoaneurysm (PSA) near the origin of the inferior epigastric artery (arrow) in a patient with bleeding after an attempted femoral line. (b) Angiography shows coils placed distal to the PSA (arrow) to prevent retrograde filling through collaterals. (c) Postembolization angiography shows successful exclusion of the PSA using the sandwich technique and dense coil packing (arrow). As the lesion was close to the origin of the vessel, detachable coils were used.

proximal embolization is performed, usually with coils. In injured small arteries of the solid organs or pelvis, distal embolization with Gelfoam, particles, or glue is performed, followed by proximal embolization.

In the presence of traumatic AVFs, particle or glue embolization is contraindicated due to the risk of pulmonary embolization in peripheral AVF, and arterial embolization with a potential stroke in pulmonary AVFs. Detachable coils or plugs are generally used; if those are not available, an oversized anchor coil can be placed followed by softer and smaller coils.

\section{Embolization Agents}

Embolization agents are classified as temporary or permanent agents. Temporary agents include autologous blood clots and gelatin sponge. Permanent agents include metallic coils, plugs, particles, and glue. In general, large vessel embolization requires coils or plugs; smaller vessels can be treated with microcoils or microplugs, particles, gelatin sponge, or glue. Stent grafts are occasionally used when vessel sacrifice is not possible.

\section{Surgical Sponge}

Gelatin sponge was one the first embolization agents used and is still one of the most used agents in trauma. ${ }^{11}$ It is inexpensive, readily available, and easy to use. Gelfoam is a surgical sponge derived from a biologic substance made as a gelatin of purified porcine skin. It is a highly porous structure with no intrinsic hemostatic action that induces thrombosis when in close contact with platelets. ${ }^{12}$ After the initial vessel thrombosis, an inflammatory foreign body reaction develops that peaks at 20 days and usually resolves by 45 days in animal studies. ${ }^{13}$ Vessel recanalization after Gelfoam embolization is usually seen within 2 weeks but may range from 3 weeks to 4 months. Permanent vessel occlusion has also been reported. ${ }^{13,14}$
Gelfoam is used to expedite embolization of the hypogastric arteries in pelvic injuries; it is also used to achieve distal embolization in smaller branches of the solid organs and extremities, usually followed by more proximal coil embolization. Gelfoam is also used after placement of coils to reinforce thrombosis, especially in patients with coagulopathy where coils alone may not provide adequate vessel occlusion. ${ }^{10}$

The main disadvantage of Gelfoam is that the sizes of the particles are not uniform and disruption of the clot with rebleeding is possible. Use of Gelfoam may also increase the risk of infection in some situation where the tissue necrosis and open contamination can promote bacterial growth.

The Gelfoam powder should not be used in trauma as the small particle size increases the risk of necrosis. Gelfoam is available as packaged sheets of different sizes that can be prepared by three main methods:

Cutting method: Using scissors, the agent is cut into multiple small 1- to 2-mm cubes; the cubes are placed in a cup or syringe and then mixed with contrast material in a 3- to 5-mL syringe. When Gelfoam sheets are cut with scissors into small cubes without forcefully pumping them, the particles will have a size distribution ranging between 500 and $2,000 \mu \mathrm{m} .{ }^{14,15}$

Pumping method: Forcefully mixing fragments of Gelfoam with contrast material using a three-way stopcock creates a slurry. Small cubes, longer pieces, or even a larger $2 \times 2 \mathrm{~cm}$ piece of Gelfoam is placed in a 5-mL syringe and the air is squeezed out, and then the agent is then forcefully mixed with contrast material (-Fig. 5). The more the agent is pumped, the more the smaller than $500 \mu \mathrm{m}$ particles are created. To further decrease the size of the particles, the slurry can be made thinner by adding more contrast and/or partially closing the three-way stopcock, while the agent is mixed forcefully back and forth between the syringes. The pumping method produces smaller particles that are less uniform in size than the cutting method. ${ }^{15}$ 

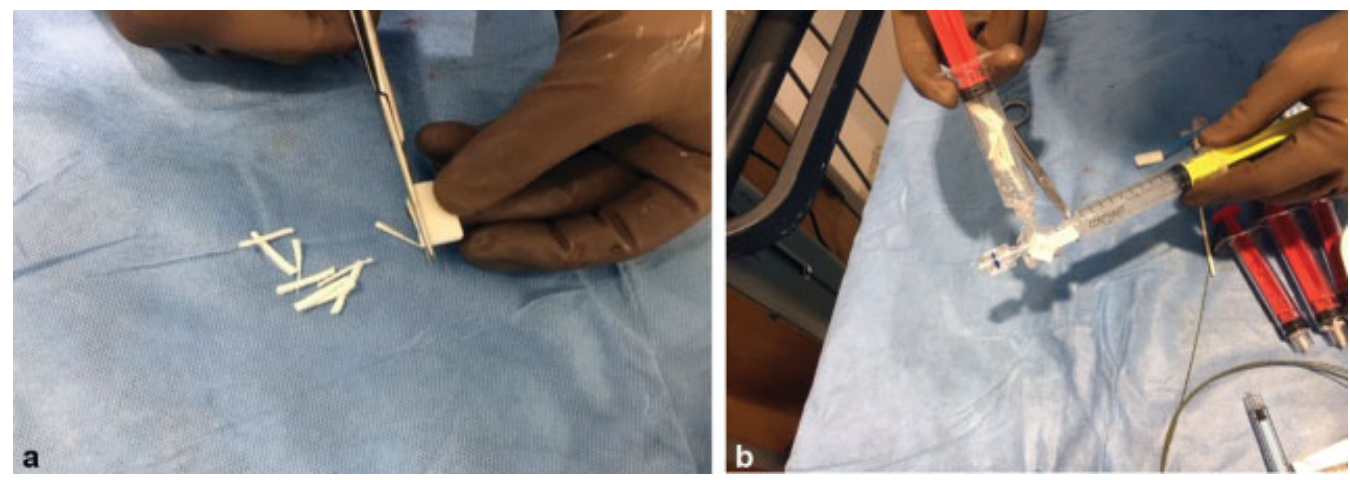

Fig. 5 Gelfoam preparation (cutting and pumping). (a) In this example, long, thin pieces of Gelfoam are cut with scissors; a larger block can also be used. (b) The pieces are loaded in the back of a syringe. (c) The air is squeezed out of the syringe and the Gelfoam compressed. (d) Contrast and Gelfoam are mixed to create a slurry.

Torpedoes: A longer piece of Gelfoam is cut from the sheet with scissors and then rolled by hand to create a "torpedo." The piece is back loaded in the 1-mm hub of the syringe to facilitate injection into catheter. Sometimes the torpedos are difficult to load and can result in catheter occlusion. Preloaded torpedos are available commercially in 2.5- and 5.0-mm diameters and $10-$ and $20-\mathrm{mm}$ lengths (Merit Medical) that greatly facilitate the loading and placement, but are more expensive.

\section{Particles}

Particles are commonly used for the treatment of nontraumatic conditions such as uterine and prostatic artery embolization and treatment of tumors, and are used occasionally in trauma. The particles are more uniform in size than Gelfoam and produce a permanent occlusion of the vessel by mechanical occlusion and inflammatory reaction, with varying degrees of proximal or distal embolization depending on the size and type of the particles used. ${ }^{16}$ Commercial particles are made of polyvinyl alcohol, tris-acryl gelatin, sodium acrylate, polyethylene glycol, or hydrogel materials. Most vials are calibrated sizes within a $200-\mu \mathrm{m}$ range, ranging in size from 40 to $1,200 \mu \mathrm{m}$. Tightly calibrated particles are also available in sizes 40 to $1,300 \mu \mathrm{m}$ (Embozene; Varian Medical Systems, Palo Alto, CA). In most trauma applications, particles with sizes greater than $300 \mu \mathrm{m}$ are used, as smaller particles may produce distal ischemia. Although there are major differences in the physical properties between the different types of commercial spheres that may explain the different levels of occlusion observed in vivo, in trauma applications none of the commercially available particles has shown a significant advantage over the others, and the operator can use any particles that are available at their practice and that they are familiar with their use. Particles are prepared by mixing them with contrast material, usually by adding 5 to $10 \mathrm{~mL}$ of contrast to the 2- to $5-\mathrm{mL}$ prefilled particle suspension. Using a three-way stopcock attached to a smaller 1- to 5-mL syringe, the solution is further mixed. The smaller syringe is used to inject small aliquots of the particles under careful fluoroscopic guidance. Constant agitation and remixing is very important to prevent particle aggregation.

Principles of Particle and Gelfoam Embolization in Trauma Embolization is a dynamic process that requires a careful technique with proper embolic material selection, stable catheter position, and constant fluoroscopic visualization to prevent serious complications from nontarget embolization.

After selective catheterization of the bleeding area, a test injection of contrast material is performed to ensure proper catheter position and identify potential reflux into nontarget areas. The speed and characteristics of the blood flow are assessed.

Embolic materials are slowly injected using small "puffs," and the flow of the contrast material mixed with embolic material is visualize constantly until partial stasis is achieved.

After the particles or Gelfoam is injected, the catheter is flushed with normal saline. This is usually performed under fluoroscopic guidance until the opacified embolic material is no longer seen; this implies that the system is "purged" or clean of the embolization material. Plan to achieve partial stasis first. It is very important that the operator avoids injecting excessive amounts of embolic materials to achieve a fast complete stasis, as the lumen of the microcatheter or main catheter still needs to be flushed clean off the embolic material, any further injections into an occluded system will result in nontarget embolization. Avoid removing a catheter full of particles that can also result in nontarget embolization, with potentially catastrophic events when working near the head and neck vessels.

Not uncommonly the particles or Gelfoam can clump together and occlude the catheter; this can happen inside the lumen or at the hub catheter. Intermittent flushing of the system with normal saline after each syringe load of particle or Gelfoam injection can help prevent this problem. In cases of severe resistance, carefully flushing the system using a small 1-mL syringe helps clear the blockage in most cases. Avoid forcefully injecting saline with larger syringes as the explosive relief of the obstruction may result in significant reflux with nontarget embolization. Embolization is a dynamic process that changes over time, fast flowing areas will become 

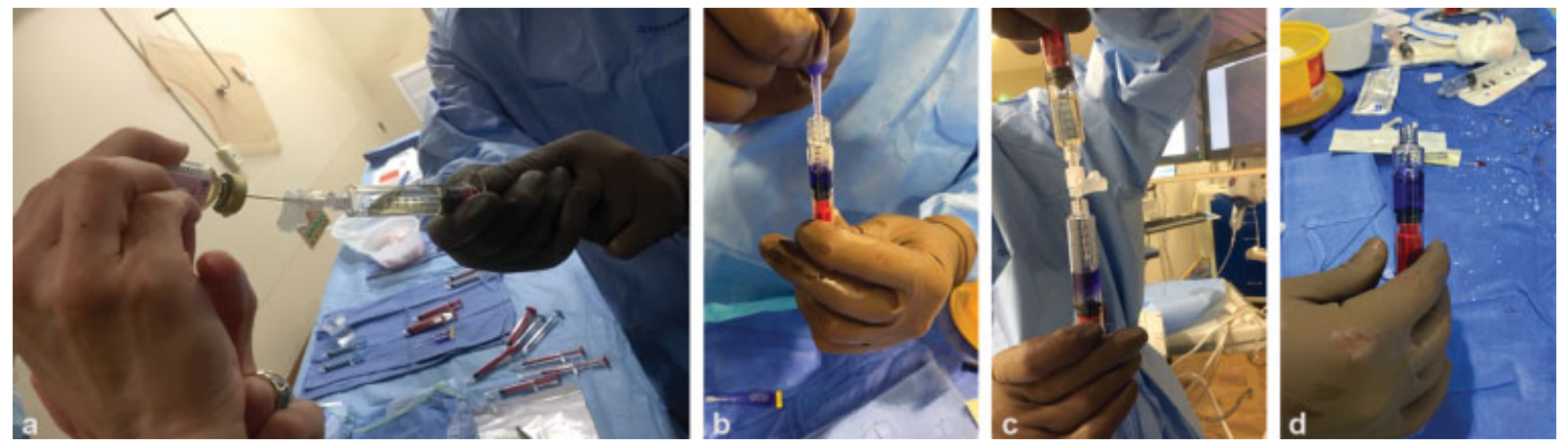

Fig. 6 Glue preparation: (a) Lipiodol is drawn in a 10-mL syringe. (b) Histoacryl plastic vial is squeezed inside a syringe; each vial has $0.5 \mathrm{~mL}$ of glue. (c) Glue and lipiodol are mixed in a syringe in a glue:lipiodol ratio of 1:3 for most trauma applications. (d) The agents are mixed by turning the syringe upside down.

stagnant, and vessels that are not initially seen clearly will become occluded with additional embolization.

\section{Liquid Embolic Materials}

Absolute alcohol and other sclerosing materials have no role in the treatment of traumatic injuries due to a significant risk of distal tissue necrosis. N-butyl cyanoacrylate (glue) (Trufill; Cordis Corp., Miami, FL; Histoacryl, B Braun Medical, Inc., Bethlehem, PA) and ethylene vinyl alcohol copolymer (Onyx; Medtronic Medical Devices, Minneapolis, MN) have been used in the treatment of selected traumatic injuries and are especially useful for patients with coagulopathy. In our practice, as the experience with glue has grown, we commonly use glue for the treatment of splenic injuries and other small branch embolization. The advantages of glue are that a very fast and reliable permanent embolization can be achieved, with distal and proximal embolization with a single injection. Main disadvantages of glue are the cost, the steep learning curve, and the need to replace the microcatheter after each injection. Histoacryl (Lipiodol; Guerbet, Princeton, $\mathrm{NJ}$ ) is a very inexpensive form of glue that is FDA approved for skin closure and has been extensively used outside the United States for multiple vascular applications. We use this agent in an off-label form. Although Histoacryl itself is inexpensive, ethiodized oil, which is often mixed with glue or Histoacryl, is a costly material in the United States, limiting a more widespread use of these materials for embolization.
Glue is mixed with lipiodol usually in a 1:3 concentration for most trauma applications and in a 1:2 concentration for faster flow injuries. Dextrose $5 \%$ is used to flush the system as glue precipitates when it comes in contact with saline or blood (-Fig. 6). Glue is injected with a smaller syringe in a constant slow infusion. In most peripheral applications, the risk of occluding the catheter in place is very low; more commonly a fragment of glue may be stuck in the tip of the catheter, with the risk of nontarget embolization when the catheter is removed ( - Fig. 7 ). Occasionally in some traumatic injuries in the spleen and liver, small AVFs that were not clearly apparent until the embolization was started may result in nontarget glue embolization into the portal vein or pulmonary arteries of small glue droplets; most of the time this is of no clinical consequence. However, if an AVF is seen on the initial angiogram, glue or particle embolization is not recommended.

Ethylene vinyl alcohol (Onyx, Medtronic) is a nonadhesive liquid copolymer dissolved in DMSO (dimethyl sulfoxide) and suspended with micronized tantalum powder. It is mainly used for the treatment of brain and peripheral AVMs. Its high cost, the need to pre shake the vials for 20 minutes before use, and the need for a DMSO-compatible delivery microcatheter severely limit its applications in trauma. A newer precipitating hydrophobic injectable liquid (PHIL; Terumo Medical, Somerset, NJ) is available as a ready-to-use nonadhesive copolymer. It is dissolved in DMSO, does not require any preparation, and is covalently bound to its iodine component, which
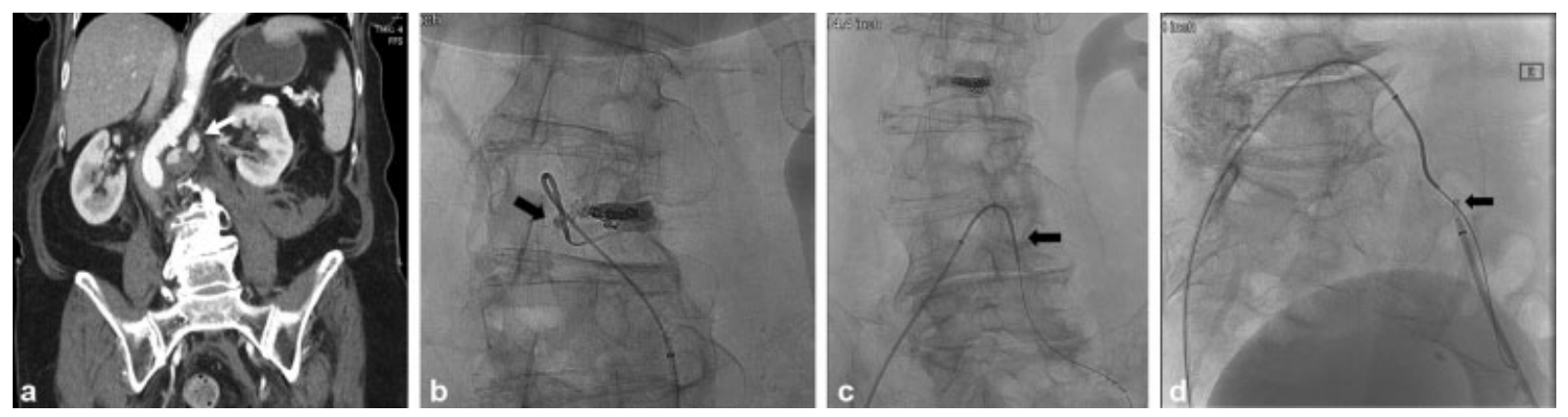

Fig. 7 An 83-year-old woman fell at home. She was on oral anticoagulation and was experiencing back pain and acute anemia. (a) CT demonstrated pseudoaneurysm of a left lumbar artery (arrow). (b) After multiple coils failed to achieve stasis, glue was injected. When removing the microcatheter, a piece of glue migrated and became stuck in the tip of the SOS catheter (arrow). (c) The catheter was advanced over the iliac bifurcation into the left common iliac artery. (d) Access into the left femoral artery was obtained and a penumbra aspiration system (arrow) was used to aspirate the fragment of glue. 

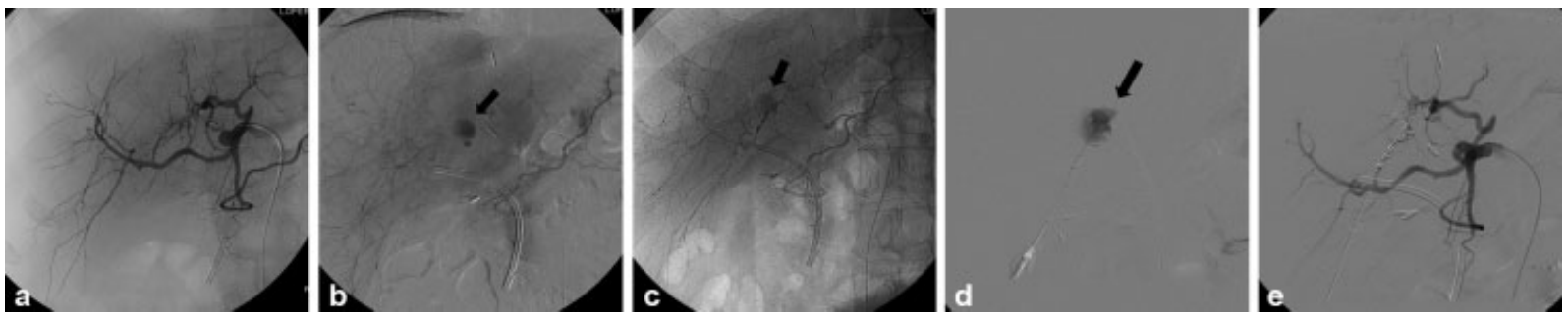

Fig. 8 Massive hemobilia after radiofrequency ablation of a liver tumor. (a and b) Hepatic angiography shows pseudoaneurysm (PSA) better seen in the delay phase (arrow). (c) Angiography after coil embolization shows persistent filling of the PSA (arrow) through multiple small branches of both right and left hepatic arteries. (d) PSA was directly punctured with a Chiba needle using ultrasound guidance and a transhepatic percutaneous approach. Contrast opacification of the PSA is seen (arrow) and then thrombin was injected. (e) Angiography after thrombin injection shows successful exclusion of the PSA.

provides its inherent radiopacity. A DMSO-compatible delivery microcatheter is also required. Experience in trauma is very limited.

\section{Thrombin}

Thrombin is derived from bovine blood and directly activates fibrinogen converting it into fibrin monomers. Thrombin is commonly used to treat femoral iatrogenic PSAs after catheterization and has been successfully used in the treatment of traumatic PSAs of the liver, spleen, and lower extremities that are not amenable to transcatheter embolization (-Fig. 8). Thrombin is available in a powder form that when reconstituted with water gives a concentration of 1,000 units in $1 \mathrm{~mL}$; additive collagen is available to provide a more concentrated mixture (D stat Flowable, Teleflex, Inc., Wayne, PA).

\section{Metallic Coils}

Metallic coils are the most commonly used embolic materials in trauma, providing a fast, reliable, and permanent vessel occlusion that is equivalent to a surgical ligation. Coils are made of steel or platinum: the former tends to be stiffer and the latter more flexible and radiopaque. Coils are available in multiple shapes and sizes. Coils induce vessel occlusion by promoting a mechanical occlusion of the blood flow that is enhanced by the presence of fibers made of different fabrics such as Dacron, wool, silk, or nylon. To achieve a complete vessel occlusion, most coils require dense packing. Coils for peripheral applications are available in 0.038 or 0.035 inch to be used with diagnostic catheters, and less than 0.022-inch sizes to be used with microcatheters.

Coils can be pushable or detachable. Pushable coils are the workhorse of the embolization in trauma, as they are easy to use and relatively inexpensive. Most coils are deployed by pushing them with a soft tip wire such as the Bentson wire. Micro coils are deployed using a special wire pusher. In relatively safe and stable positions, most micro coils can be deployed by injecting saline forcibly with a small syringe. Detachable coils allow very precise deployment and embolization of different-sized vessels. Due to its high cost, detachable coils are reserved for embolization of areas that require precise coils position and/or short landing zones, or in cases of AVF (-Fig. 4). A significant advantage of detachable coils is that in case of initial misplacement, they can be retrieved. They are also available in lengths up to $60 \mathrm{~cm}$. The main disadvantage is the high cost, especially if multiple coils are required; however, if single or fewer longer detachable coils can be placed, the time and money saved instead of using multiple regular coils can partially offset the initial cost of the detachable coil. - Tables $\mathbf{1}$ and $\mathbf{2}$ show the most commonly used pushable and detachable coils.

\section{Tips and Tricks for Coils}

Always use an introducer sheath for arterial access to facilitate catheter exchanges and for the occasional event when the coil becomes stuck in the catheter, to allow removing the catheter with the coil without losing arterial access.

Table 1 Examples of commonly used pushable coils

\begin{tabular}{|l|l|l|l|}
\hline $\begin{array}{l}\text { Tornado } \\
\text { (Cook, Inc., Bloomington, IN) }\end{array}$ & 0.018 and 0.035 & $\begin{array}{l}\text { Diameter: } 3-10 \mathrm{~mm} \\
\text { Length: up to } 14 \mathrm{~cm}\end{array}$ & Tapers in one end \\
\hline $\begin{array}{l}\text { MReye } \\
(\text { Cook) }\end{array}$ & 0.035 and 0.038 & $\begin{array}{l}\text { Diameter: } 2-20 \mathrm{~mm} \\
\text { Length: up to } 15 \mathrm{~cm}\end{array}$ & $\begin{array}{l}\text { High radial force } \\
\text { Anchor coil }\end{array}$ \\
\hline $\begin{array}{l}\text { Nester } \\
(\text { Cook) }\end{array}$ & 0.018 and 0.035 & $\begin{array}{l}\text { Diameter: } 2-20 \mathrm{~mm} \\
\text { Length: up to } 20 \mathrm{~cm}\end{array}$ & Soft, radiopaque, filling coil \\
\hline $\begin{array}{l}\text { Vortex } \\
\text { Boston Scientific, Marlborough, MA) }\end{array}$ & 0.018 and 0.035 & $\begin{array}{l}\text { Diameter: } 2-20 \mathrm{~mm} \\
\text { Length: up to } 20 \mathrm{~cm}\end{array}$ & Tapers in one end \\
\hline $\begin{array}{l}\text { Vortex Diamond } \\
\text { (Boston Scientific) }\end{array}$ & 0.018 & $\begin{array}{l}\text { Diameter: } 3-6 \mathrm{~mm} \\
\text { Length: up to } 20 \mathrm{~cm}\end{array}$ & Tapers in both ends \\
\hline $\begin{array}{l}\text { Complex Helical } \\
\text { (Boston Scientific) }\end{array}$ & 0.018 and 0.035 & $\begin{array}{l}\text { Diameter: } 4-11 \mathrm{~mm} \\
\text { Length: up to } 7 \mathrm{~cm}\end{array}$ & Framing coil \\
\hline
\end{tabular}


Table 2 Examples of commonly used detachable coils

\begin{tabular}{|c|c|c|c|c|}
\hline Name & $\begin{array}{l}\text { System } \\
\text { requirement }\end{array}$ & Detachment & Sizes and shapes & Comments \\
\hline $\begin{array}{l}\text { Interlock } \\
\text { (Boston } \\
\text { Scientific) }\end{array}$ & $\begin{array}{l}\text { Diagnostic } \\
\text { catheter and } \\
\text { microcatheter }\end{array}$ & $\begin{array}{l}\text { Locking mechanism detached } \\
\text { by advancing coil past the tip of } \\
\text { the catheter } \\
\text { Avoid advancing the pusher } \\
\text { too deep into the coils package } \\
\text { as the notch can become } \\
\text { entangled in the coils }\end{array}$ & $\begin{array}{l}\text { 2D, cube, and diamond shapes } \\
\text { Size: } 2-22 \mathrm{~mm} \\
\text { Length: up to } 60 \mathrm{~cm}\end{array}$ & $\begin{array}{l}\text { Very thrombogenic, made of } \\
\text { platinum, highly visible, relatively } \\
\text { rigid, a nonfibered softer version } \\
\text { recently available with } \\
2-5 \text { diameter in sizes and up to } \\
12 \mathrm{~cm} \text { in length }\end{array}$ \\
\hline $\begin{array}{l}\text { Concerto } \\
\text { (Medtronic) }\end{array}$ & Microcatheter & $\begin{array}{l}\text { Bell and socket locking system, } \\
\text { released by a separate handle }\end{array}$ & $\begin{array}{l}\text { Helical and 3D } \\
\text { Diameter: } 2-20 \mathrm{~mm} \\
\text { Length: up to } 50 \mathrm{~cm}\end{array}$ & $\begin{array}{l}\text { Extremely soft, allows emboliza- } \\
\text { tion of very small and tortuous } \\
\text { vessels } \\
\text { Coils are not very thrombogenic, } \\
\text { require dense packing. Available } \\
\text { with polymer fibers to increase } \\
\text { thrombogenicity }\end{array}$ \\
\hline $\begin{array}{l}\text { Ruby } \\
\text { (Penumbra) }\end{array}$ & $\begin{array}{l}\text { High flow } \\
\text { and regular } \\
\text { microcatheter }\end{array}$ & $\begin{array}{l}\text { Standard and soft } \\
\text { Deployed by a click in a } \\
\text { separate handle }\end{array}$ & $\begin{array}{l}\text { Ruby } \\
\text { POD for high-flow lesions } \\
\text { Packing coil } \\
\text { Diameter: } 1-40 \mathrm{~mm} \\
\text { Length: up to } 60 \mathrm{~cm}\end{array}$ & $\begin{array}{l}\text { Large-volume coil, requires a large } \\
\text { lumen microcatheter } \\
\text { Low-profile system recently } \\
\text { available that allows using a } \\
\text { regular } 0.021 \text { microcatheter }\end{array}$ \\
\hline $\begin{array}{l}\text { Azur } \\
\text { (Terumo) }\end{array}$ & $\begin{array}{l}\text { Diagnostic } \\
\text { catheter and } \\
\text { microcatheter }\end{array}$ & $\begin{array}{l}\text { Deployed by a click in a } \\
\text { separate handle }\end{array}$ & $\begin{array}{l}\text { Framing for aneurysms } \\
\text { Hydrocoil (filling and packing) } \\
\text { and CX (anchor) } \\
\text { Diameter: } 2-20 \\
\text { Length: up to } 40 \mathrm{~cm}\end{array}$ & $\begin{array}{l}\text { Hydrogel expands } 4-5 \text { times the } \\
\text { original size in the presence of } \\
\text { blood }\end{array}$ \\
\hline $\begin{array}{l}\text { Retracta } \\
\text { (Cook) }\end{array}$ & $\begin{array}{l}\text { Diagnostic } \\
\text { catheter }\end{array}$ & $\begin{array}{l}\text { Deployed by manually } \\
\text { unscrewing a cable } \\
\text { with a torque } 8-10 \text { times } \\
\text { counter clockwise }\end{array}$ & $\begin{array}{l}\text { Diameter: } 4-20 \mathrm{~mm} \\
\text { Length: up to } 14 \mathrm{~cm}\end{array}$ & $\begin{array}{l}\text { Test injection is possible before } \\
\text { deployment using a Y adaptor }\end{array}$ \\
\hline
\end{tabular}

Avoid using a catheter with side holes, as the coil may become wedged inside the side hole and it will not deploy.

When loading the coil, make sure that the coil delivery system is well positioned inside the hub of the catheter; the operator also needs to hold the two systems firmly to avoid deploying part of the coil inside the hub of the catheter resulting in catheter occlusion and coil damage.

Accurate vessel sizing is very important. Most operators estimate the size of the coil visually. Using a coil slightly larger than the vessel is recommended. Softer coils can be oversized by 20 to $30 \%$, but stiffer oversized coils may be deployed elongated in the vessel preventing dense packing. Also a coil that is too large will push the catheter back and may cause nonintentional proximal embolization or migration of the coil into a critical vessel (-Fig. 9). A coil that is too small for the vessel may migrate distally; most of the time this is not very relevant unless an AVF is present.

Most 0.018 microcoils are placed through microcatheters with a 0.021 -inch lumen. Many of the pushable microcoils and some of the detachable coils may become "jammed" inside the lumen of a larger diameter 0.027-inch microcatheter. Ruby coils (Penumbra, Inc., Alameda, CA)
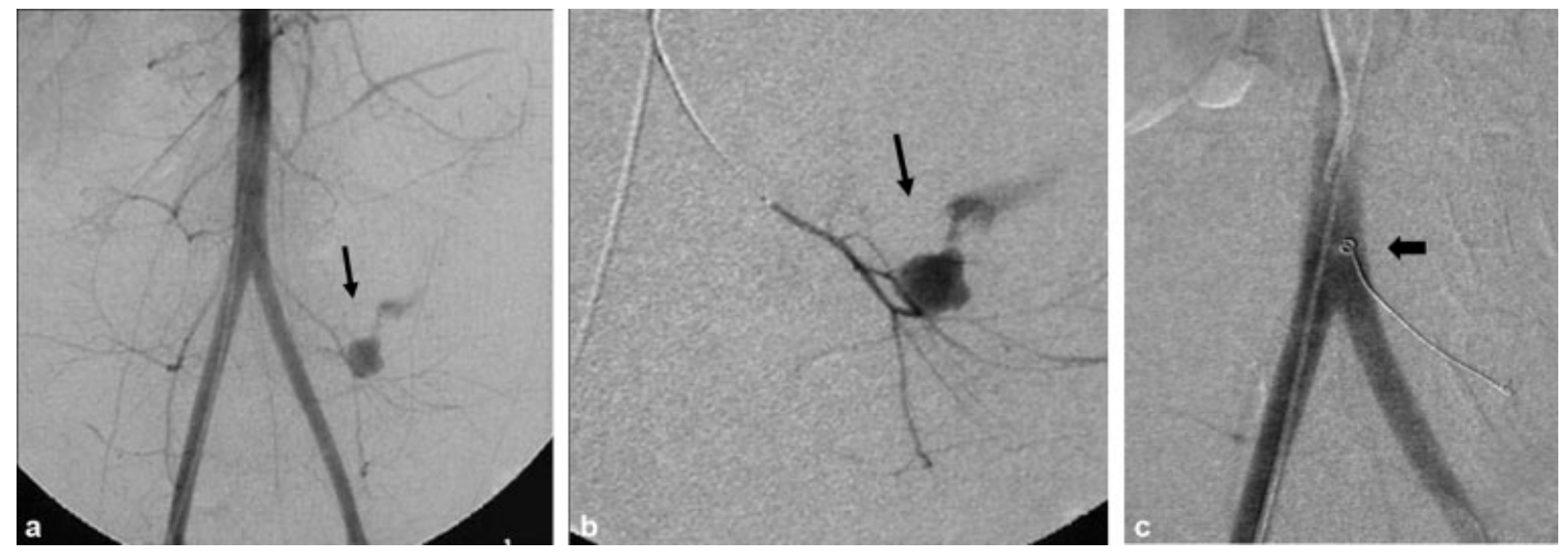

Fig. 9 (a) Aortogram shows a pseudoaneurysm (PSA) of an iliolumbar artery (arrow). (b) Selective catheterization performed with a microcatheter redemonstrates the PSA. (c) A long pushable microcoil was placed, which protruded into the aorta (arrow). The operator decided to leave the coil in that place, as the patient had multiple other injuries. 
are of 0.022 inch and require a high flow microcatheter; recently, 0.018-inch coils also became available from that company.

Ensure a stable catheter position to prevent the coil from kicking back the catheter into a more proximal vessel, resulting in nontargeted embolization. If unsure about the stability of the system, it is always better to start with a shorter and softer coil to test the system. Placing coils using a microcatheter adds stability to the system. If there are doubts about the stability of the system and the catheter is close to a critical vessel, use a detachable coil system that will allow repositioning before final release.

If you notice that the coil is kicking back the catheter, firmly hold the system to force the coil to form inside the vessel lumen. If the coil keeps kicking back the system, many of the detachable coils can be used as a wire to allow advancing the microcatheter distally over the partially deployed coil and then reattempting to deploy the coil more distally. If the problem persists, retrieving the first coil and replacing it with a smaller and shorter coil will resolve this issue.

Pushable coils cannot be repositioned if misplaced, and coil retrieval using a snare may be required in some cases. If the coil is not completely out of the catheter, sometimes the combination of coil and catheter can be gently advanced forward to try to engage the target vessel. If the coil is protruding from the tip of the catheter, it may be possible to remove both from the sheath as a unit. Careful fluoroscopic guidance is necessary to ensure that the coil is not displaced out of the catheter when crossing the access sheath.

Make sure that the coil is completely deployed by advancing the guide wire past the distal end of the catheter by a few millimeters to ensure that tail of the coil is not still inside the catheter, to avoid inadvertently pulling the coil out of the target when removing the catheter. However, do not advance the wire too distally to prevent the coils being pushed distally away from the target area.

Compact coiling is very important to avoid vessel recanalization (-Fig. 4). Coils are available in multiple shapes that allow filling of the lumen of the vessels. Coils range from a 1 -mm segment to complex shaped coils up to $22 \mathrm{~mm}$ in diameter. Most companies have framing or anchor coils that are stronger for initial deployment, and softer packing or filling coils designed to fill up the lumen of the vessel.

Complete vessel thrombosis may take a few minutes. Although at times additional coiling may be required, waiting a few minutes and/or pulling the catheter back a few millimeters to avoid injecting the contrast material inside the coils is all it takes to demonstrate vessel occlusion.

\section{Embolization Plugs}

\section{Amplatzer Vascular Plugs}

Amplatzer Vascular Plug (AVP; Abbott Laboratories, Abbott Park, IL) are disks of braided nitinol that cause vessel thrombosis by mechanical occlusion of the blood flow. The more layers the disk has, the more thrombogenic it becomes. The disk is attached to a cable with a screw, and it is deployed by rotating
Table 3 Types of Amplatzer vascular plugs

\begin{tabular}{|l|l|l|l|}
\hline AVP & $\begin{array}{l}\text { Diameters } \\
(\mathrm{mm})\end{array}$ & Sheath & Comments \\
\hline 1 & $4-16$ & $5-8 \mathrm{Fr}$ & $\begin{array}{l}\text { For vessels up to } 17 \mathrm{~mm} \\
\text { Two layers, least } \\
\text { thrombogenic, ideal for } \\
\text { short landing zones }\end{array}$ \\
\hline 2 & $3-22$ & $4-7 \mathrm{Fr}$ & $\begin{array}{l}\text { For vessels up to } 17 \mathrm{~mm} \\
\text { Six layers, takes more } \\
\text { space, more } \\
\text { thrombogenic }\end{array}$ \\
\hline 4 & $4-8$ & $\begin{array}{l}4-5 \mathrm{Fr}, 0.038 \\
\text { diagnostic } \\
\text { catheter }\end{array}$ & $\begin{array}{l}\text { For vessels up to } 6 \mathrm{~mm} \\
\text { Double layers }\end{array}$ \\
\hline
\end{tabular}

Abbreviation: AVP, Amplatzer Vascular Plug.

the cable in a counter clock way until the plug is released. Before release the plug can be retrieved easily. It is also possible in special circumstances to compact or elongate the disk within the vessel wall. ${ }^{17}$ In the United States, three types of plugs are available (-Table 3 ). Although the cost of each plug is high, many times one plug is enough to achieve vessels thrombosismultiple coils may be otherwise required, saving significant time, radiation exposure, and potentially cost.

It is recommended to oversize the plug 30 to $50 \%$ of the vessel diameter at the occlusion site. The main uses of AVP in trauma include the occlusion of relatively large vessels such the splenic artery, the renal artery, and peripheral AVF where using coils has a higher risk of accidental embolization (-Fig. 10). The main disadvantage of the AVP is that the device is relatively stiff compared with regular coils and requires precise placement of a guiding catheter or sheath past the target area; this can be difficult to achieve inside tortuous vessels. To overcome this problem, the type 4 AVP was released to allow placement of the plug using a regular diagnostic catheter with sizes up to $8 \mathrm{~mm}$.

The first-generation AVP is a two-layer disk which requires the shortest landing zone but is the least thrombogenic. The second-generation devices have a three-disk configuration, which includes additional thinner disks attached at the end of the plugs for additional cross-sectional material making them more thrombogenic. The AVP 4 allows to place the plug in distal and tortuous areas using a diagnostic catheter. A micro plug that can be deployed through a 2.9-Fr microcatheter became recently available in 3-, 4-, 5-, and 6-mm sizes.

\section{Newer Plugs}

Plugs with attached membranes to increase thrombogenicity are available, and experience in trauma is very limited.

\section{MVP Microvascular Plug}

The MVP microvascular plug (Medtronic) was introduced in 2013; it is a nitinol cage covered by a polytetrafluoroethylene (PTFE) membrane at its proximal portion. The plug is deployed by withdrawing the delivery catheter and rotating the pusher wire in a counter-clockwise direction. Similar to the AVP, it can be easily resheathed and redeployed if necessary prior to its release. It comes in diameters of 3, 5, 

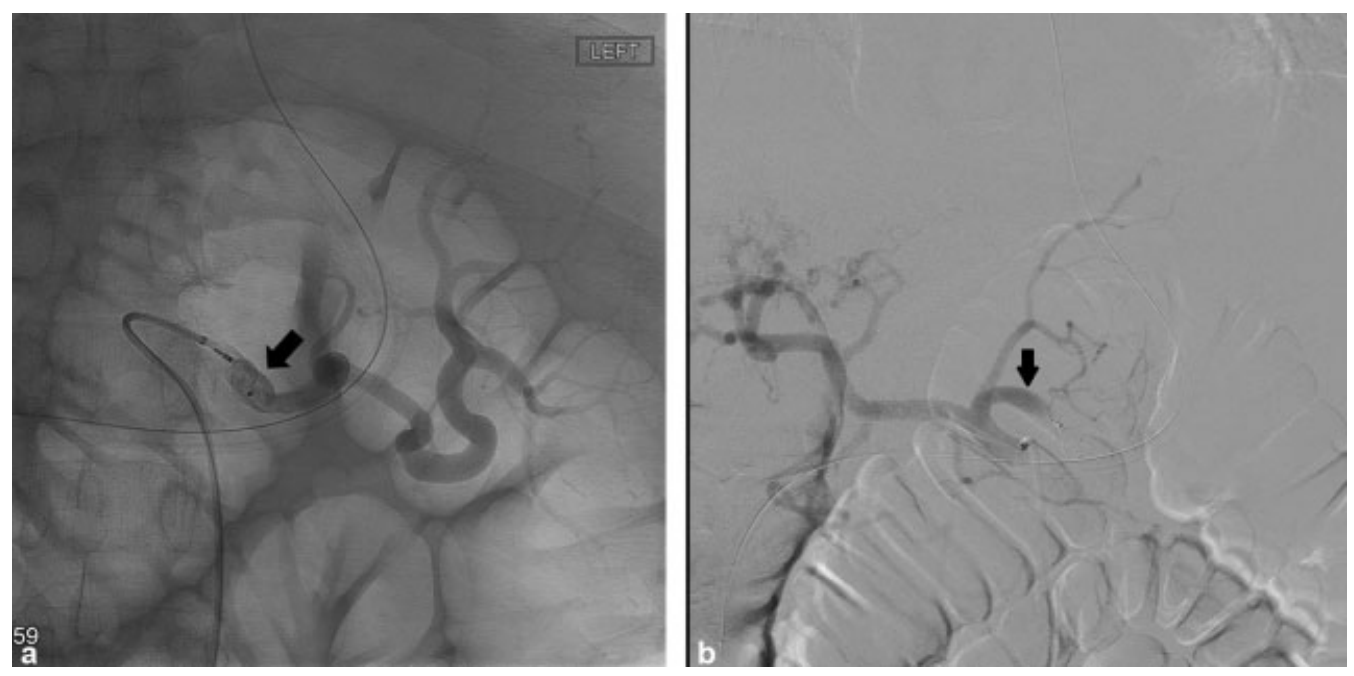

Fig. 10 (a) Proximal splenic artery embolization using AVP II (arrow). (b) Digital subtraction angiography shows successful occlusion of the splenic artery (arrow).

7 , and $9 \mathrm{~mm}$ for vessels with diameters from 1.5 to $9 \mathrm{~mm}$. The 3- and $5-\mathrm{mm}$ can be used with microcatheters with 0.021 and 0.027-inch inner diameters; the 5- and 9-mm can be placed through standard 4- and 5-Fr 0.038 catheters.

\section{Caterpillar}

The Caterpillar (Bard Medical, Covington, GA) device has a double body shape with a polyurethane and polyethylene occlusion membrane in one end. The micro version can be deployed through a 0.027 microcatheter for vessel from 1.5 to $4 \mathrm{~mm}$; the 3- to 6-mm version can be deployed through a 0.038 catheter; and the larger versions $5-$ to $7-\mathrm{mm}$ vessels require a 0.056 -inch inner lumen guiding catheter. Due to its design, this device requires longer landing zones between 16 and $37 \mathrm{~mm}$.

\section{Impede}

The Impede plug (Shape Memory Medical, Santa Clara, CA) is hybrid between a coil and a plug with a porous polymer scaffold that is available without the coil part also. It comes in three sizes for vessel 2 to $10 \mathrm{~mm}$ and is placed using catheters with inner diameter of 0.038 to 0.070 .

\section{EOS}

The EOS plug (ArtVentive Medical Group, Inc., San Marcos, CA) is a corkscrew nitinol frame with a PTFE membrane. Also comes in three sizes with 9 to $18 \mathrm{~mm}$ lengths for vessels between 3 and $11 \mathrm{~mm}$ requiring a 6 - to 7.5 -Fr guiding catheter.

\section{Stent Grafts in Trauma}

Although not embolization agents per se, stent grafts or covered stents can provide a rapid and potentially life- and limb-saving tamponade of bleeding injuries of vessels that cannot be sacrificed. Covered stents have been used in the endovascular treatment of PSA, AVF, and vessel transections. The main indications of stent grafts in trauma are the treatment of traumatic injuries of medium and large vessels such as
Table 4 Examples of commercially available stent grafts

\begin{tabular}{|c|c|c|c|}
\hline & $\begin{array}{l}\text { Diameter } \\
(\mathrm{mm})\end{array}$ & Length (mm) & $\begin{array}{l}\text { Introducer } \\
\text { sheaths } \\
\text { (Fr) }\end{array}$ \\
\hline \multicolumn{4}{|l|}{ Self-expandable } \\
\hline Fluency (Bard) & $6-13.5$ & $\begin{array}{l}40,60,80 \\
100,120\end{array}$ & $8-10$ \\
\hline $\begin{array}{l}\text { Viabahn (W. L. Gore } \\
\text { and Associates, } \\
\text { Flagstaff, AZ) }\end{array}$ & $5-13$ & $\begin{array}{l}25,50,75 \\
100,150,250\end{array}$ & $6-11$ \\
\hline Covera (Bard) & $6-10$ & $\begin{array}{l}30,40,60 \\
80,100\end{array}$ & $8-9$ \\
\hline \multicolumn{4}{|l|}{ Balloon expandable } \\
\hline $\begin{array}{l}\text { I Cast (Atrium } \\
\text { Health, Hudson, } \\
\text { NH) }\end{array}$ & $5-12$ & $16,22,38,59$ & $6-7$ \\
\hline VBX (Gore) & $5-11$ & $\begin{array}{l}15,19,29,39 \\
59,79\end{array}$ & $7-8$ \\
\hline Lifestream (Bard) & $5-12$ & $16,26,37,58$ & $6-8$ \\
\hline Jo Stent (Abbott) & $3-5$ & $12,16,19,26$ & 6 \\
\hline
\end{tabular}

the iliac, subclavian, and axillary arteries. ${ }^{18}$ The use of stent grafts in smaller $(<6 \mathrm{~mm})$ vessels such as the superficial femoral, popliteal, and brachial arteries is not routinely recommended due to the limited long-term patency rates. There are several commercially available self- and balloon expandable stent grafts ( - Table 4). Adequate sizing is critical with stent grafts, as stent undersizing may result in an endoleak, and stent oversizing may result in stent infolding. Potential complications of covered stent placement include stent occlusion, deformation and kinking, and loss of vessel branches after stent placement. Although rare, covered stents have also the potential of getting infected in cases of bacteremia and sepsis. The use of large introducer sheaths, the high cost of these devices, and the limited data on the long-term performance are the main drawbacks of stent grafts in trauma. 


\section{General Approach to Specific Vascular Territories}

\section{Extremity Trauma}

\section{Key Points}

Embolization agents: coils, Gelfoam.

Sandwich technique required for many muscular branches. Watch for compartment syndrome.

Can the artery be sacrificed? If not covered stents in selected cases.

Most extremity vascular injuries can be accurately diagnosed with CT. Extremity injuries are commonly associated with complex orthopaedic injuries that require prompt reduction and stabilization. Major vessels disruption with active bleeding, distal ischemia, concern for wound contamination, and/or the possibility of compartment syndrome are indications for prompt surgical repair. Endovascular repair of transected major vessels is rarely indicated; however, in patients with multiple associated injuries and vascular disruption of vessels where the surgical approach is more difficult, such as the iliac, subclavian, and axillary arteries, those vascular injuries can be safely and promptly treated with stent grafts ${ }^{18}$ (-Fig. 11). Injuries to the brachial, superficial femoral, or popliteal artery are managed with surgical repair, although the use of stent grafts in these vessels has been reported, the poor long-term patency is a major problem, especially in younger patients.

Peripheral noncritical branches such as branches of the profunda femoral, muscular branches around the shoulder, and upper arm can be safely embolized. ${ }^{19}$ Proximal and distal control is usually required to prevent distal recanalization and rebleeding. Isolated single vessel injuries of the radial, ulnar, or interosseous arteries in the upper extremities, and the tibial and peroneal arteries in the lower extremities, can be safely embolized if the distal arches supplied by the noninjured vessels are still intact. In these cases, the sandwich technique is very important to prevent distal bleeding from collateral and retrograde circulation. ${ }^{20}$ Use of stent grafts in these small branches is rarely indicated.

\section{Liver}

\section{Key Points}

Dual blood supply.

Superselective embolization with coils, Gelfoam.

Watch for anatomical variants.

Many blunt and some penetrating injuries of the liver can be safely managed with NOM in hemodynamically stable patients. ${ }^{21,22}$ Superselective embolization is always recommended in most cases unless massive diffuse bleeding is present requiring more proximal and nonselective embolization $^{23}$ (-Fig. 12). Most parenchymal liver injuries involve small or medium branches; revascularization from distal branches after proximal embolization is possible but not very common. Superselective embolization with microcoils, Gelfoam, or particles to achieve distal control followed by proximal coil embolization is recommended (-Fig. 13). High-grade liver injuries tend to be associated with portal and/or biliary injuries, and are mostly treated surgically. Surgical control of the bleeding can be challenging due to the extensive collateral circulation. If HOR is available, angiography and embolization can be performed during the initial
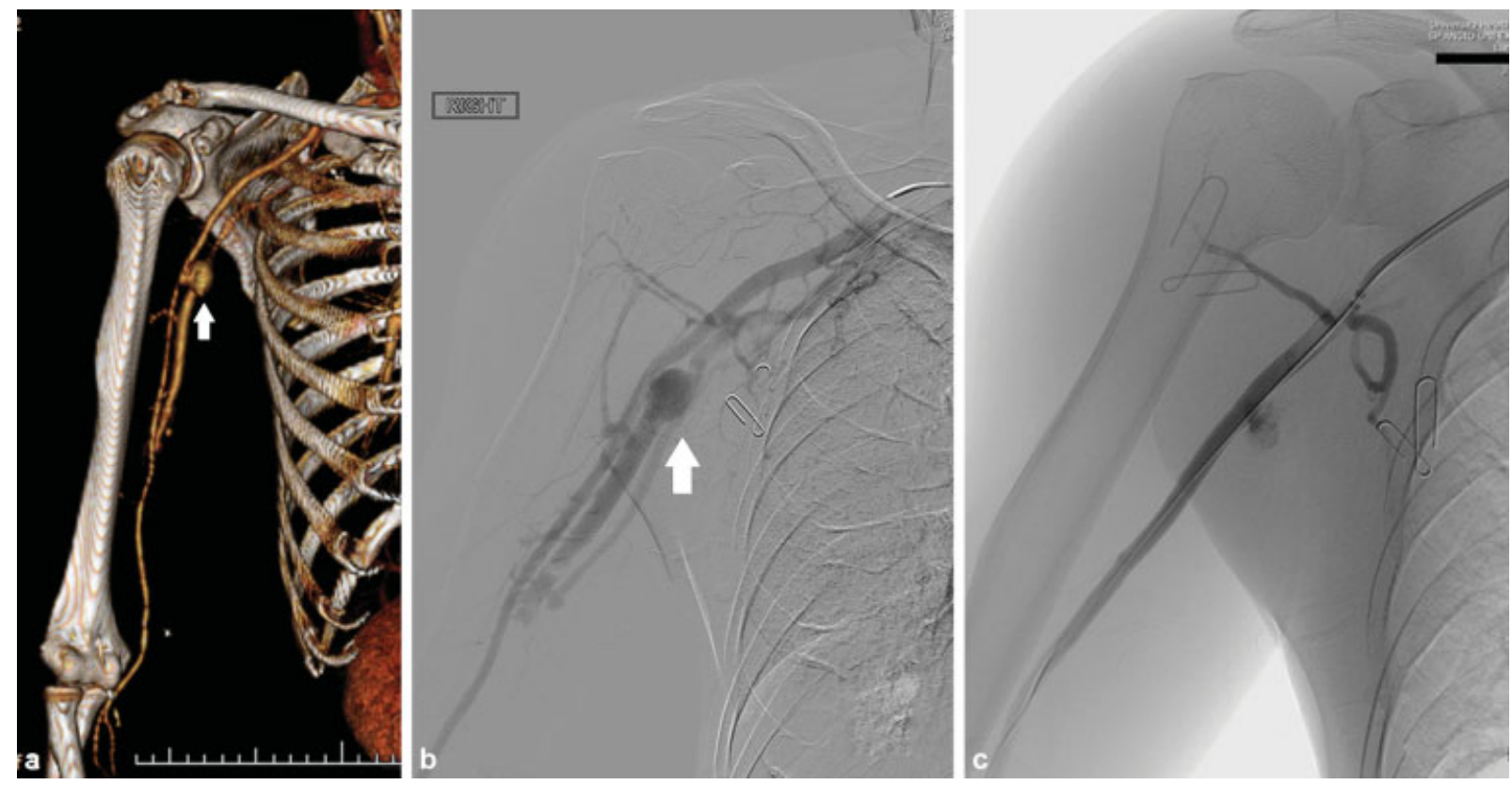

Fig. 11 (a) CTA and digital subtraction angiography (b) show pseudoaneurysm (PSA) with AVF (arrows) in the proximal brachial artery. (c) Successful exclusion of the PSA with a stent graft. Persistent pooling of contrast from prior injections is noted in the PSA. The patient later presented with occlusion of the stent 8 months later that was treated with a venous bypass. 

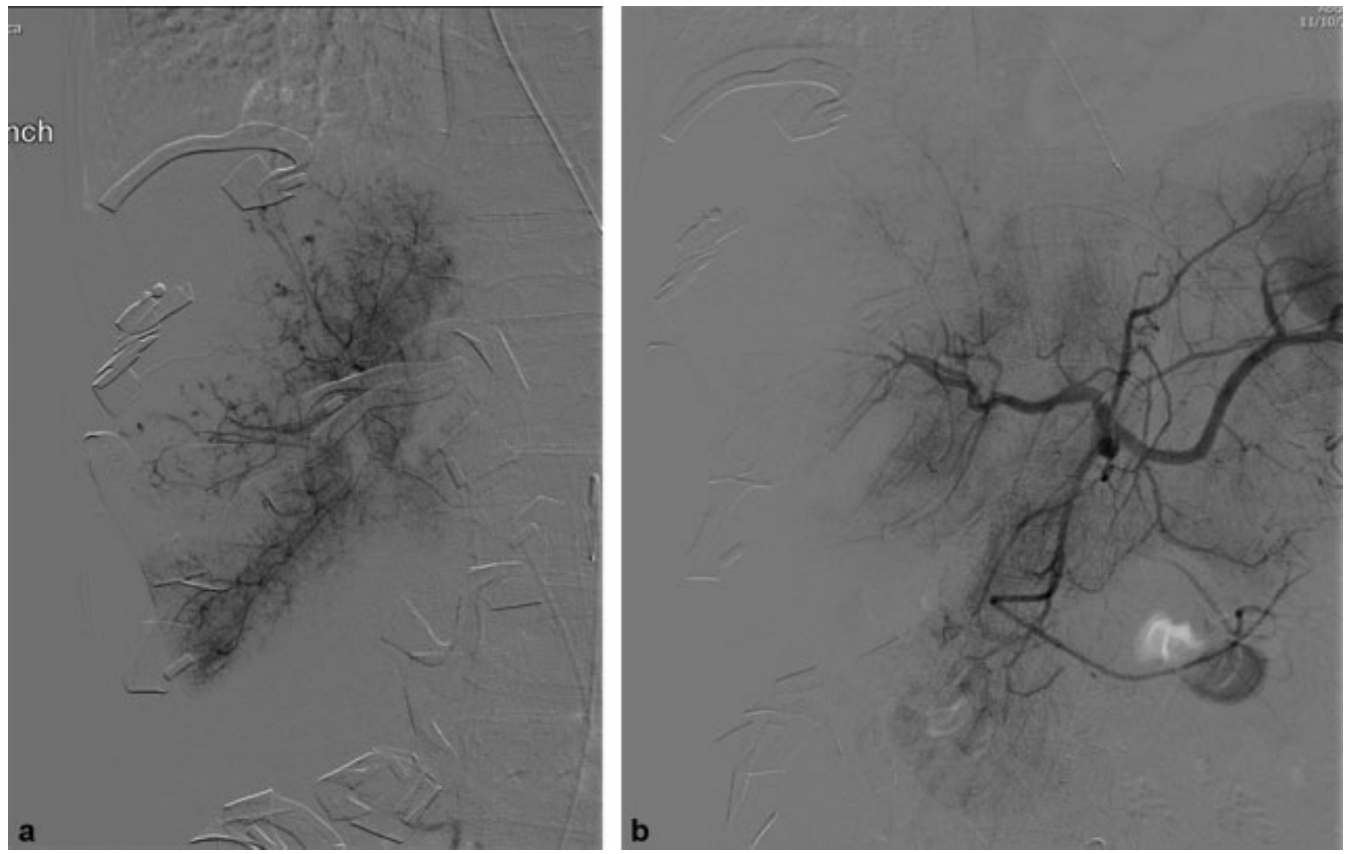

Fig. 12 (a) Digital subtraction angiography in patient with blunt liver injury that continued to bleed during surgery after surgical packing shows multiple areas of small punctate contrast extravasation in the right lobe. (b) Angiography after nonselective embolization of the right hepatic artery with Gelfoam shows exclusion of bleeding areas.
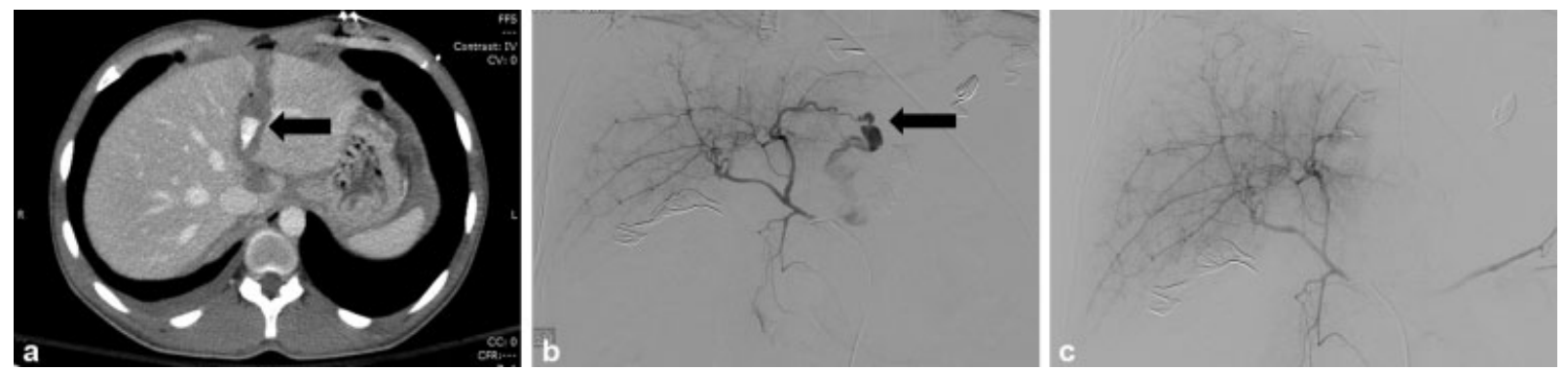

Fig. 13 (a) CT scan shows a liver laceration with active extravasation (arrow) in a patient with a gunshot wound. Patient was taken to hybrid operative room (HOR) and packed. (b) Digital angiography in the HOR demonstrates active extravasation of the left hepatic artery (arrow). (c) Digital subtraction angiography after Gelfoam and coil embolization shows successful control of the bleeding.

surgery; if the initial angiography is negative, removal of the perihepatic hemostatic packing or surgical clamps with repeat angiography can reveal the bleeding source (-Fig. 14).

Given the dual supply of the liver, extensive embolization is usually well tolerated. Hepatic necrosis, biliary and abscess, and gallbladder necrosis are reported complications. ${ }^{24} \mathrm{~A}$ potential higher incidence of hepatic necrosis has been reported with the use of Gelfoam compared with coils, but this has been highly controversial. ${ }^{25}$

\section{Spleen}

\section{Key Points}

Distal embolization: coils, Gelfoam, glue.

Proximal embolization: plugs, coils.

Rebleeding from adjacent areas not uncommon.

Splenic artery embolization is highly effective in the NOM of higher grade injuries and those associated with contrast blush in CT scans. ${ }^{26}$ The method of embolization of splenic injuriesproximal versus distal-has been a long time controversial issue in IR. In our practice, we prefer to do superselective distal embolization using microcoils \pm Gelfoam or glue ( - Fig. 15). In shattered spleens with multiple areas of contrast extravasation, proximal splenic artery embolization using coils or AVP is an acceptable option. Collateral circulation from the pancreatic, gastroduodenal, and gastric branches usually maintains distal splenic perfusion (-Fig. 16).

As a result of a rapid response system by IR, higher degrees of splenic injuries can be treated with embolization avoiding splenectomy in most cases. ${ }^{27}$ Delayed PSAs from adjacent areas that are not apparent in the initial embolization are not uncommon (15-20\%); in our institution as part of trauma protocol, patients are imaged with a contrast-enhanced CT before discharge; repeat embolization is highly effective if delayed PSAs are seen.

Fever, pleural effusion, and partial splenic infarction are not uncommon. ${ }^{28}$ Splenic abscess formation is relatively infrequent. Extensive nonselective splenic artery embolization 

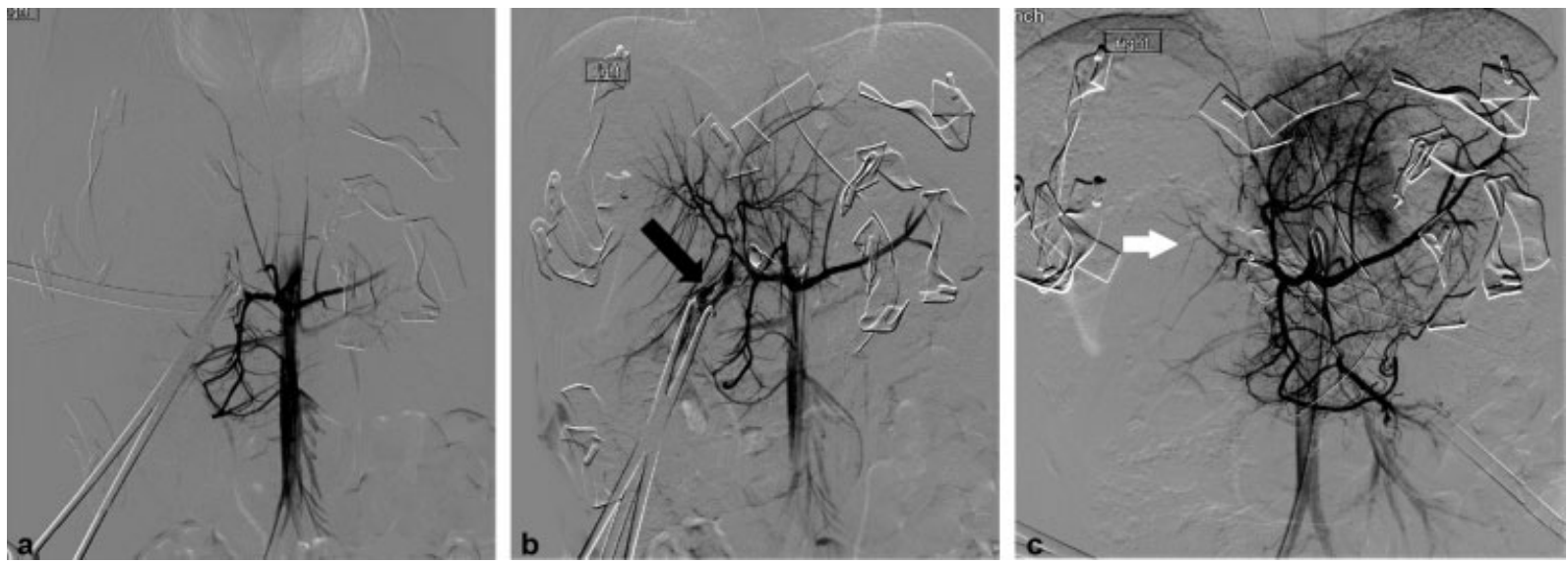

Fig. 14 (a) Digital subtraction angiography (DSA) in an 8-year-old patient with blunt liver injury that continued to bleed despite packing and clamping of the hepatic hilum shows no flow in the hepatic artery and no active bleeding. (b) After the clamp was released, repeat angiography shows active extravasation of contrast (arrow). (c) Angiography after coil embolization of the right hepatic artery shows no active extravasation. Distal reconstitution of some of the right hepatic arteries is seen (arrow).
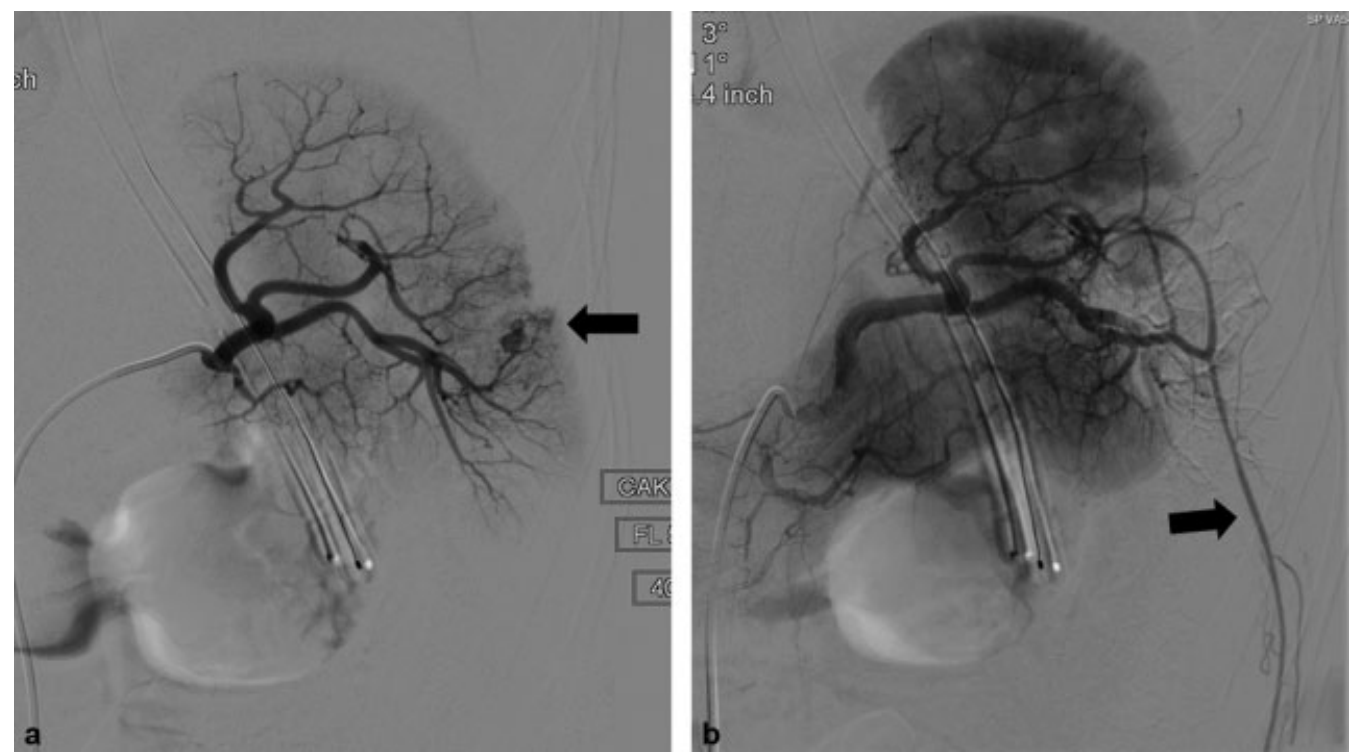

Fig. 15 (a) Digital subtraction angiography (DSA) shows pseudoaneurysm in the lower pole of the spleen (arrow). (b) DSA after glue embolization of the lower pole. When embolization of the lower pole of the spleen is performed with glue or particles, reflux into the left gastroepiploic (arrow) is a potential complication.

can result in pancreatitis as a result on nontarget embolization. $^{29}$

\section{Kidneys}

\section{Key Points}

Embolization agents: coils, Gelfoam, glue.

Terminal branches, always superselective.

Don't forget to look for accessory branches.

Many penetrating and blunt kidney injuries can be managed with $\mathrm{NOM}^{30-32}$ (- Fig. 17). Even high-degree injuries can be treated with embolization preserving some of the renal function ( - Fig. 18). Distal parenchymal injuries are treated with superselective embolization using Gelfoam, glue, or micro coils (-Fig. 18). As these are terminal branches, parenchymal infarct will occur. Rebleeding is rare but can occur from incomplete embolization, missed areas of injuries, or from collateral circulation from capsular branches. Repeat embolization is highly effective. ${ }^{33}$ As accessory renal branches are common, those can be easily missed if only the main renal artery is selected. True AVF can also occur, and detachable coils or plugs are indicated.

Major vascular and parenchymal injuries when discovered intraoperatively often result in nephrectomy. Revascularization of injuries of the main renal artery with surgical repair has a success rate of arterial repair of only 25 to $35 \%{ }^{32}$ Arterial repair should be attempted in patients with only one kidney or in those with bilateral renal injuries. Injuries less than 4 hours can be revascularized endovascularly. ${ }^{32}$ Placement of a stent graft has been controversial, ${ }^{34}$ and refractory hypertension is a long-term complication of poorly revascularized kidneys. 

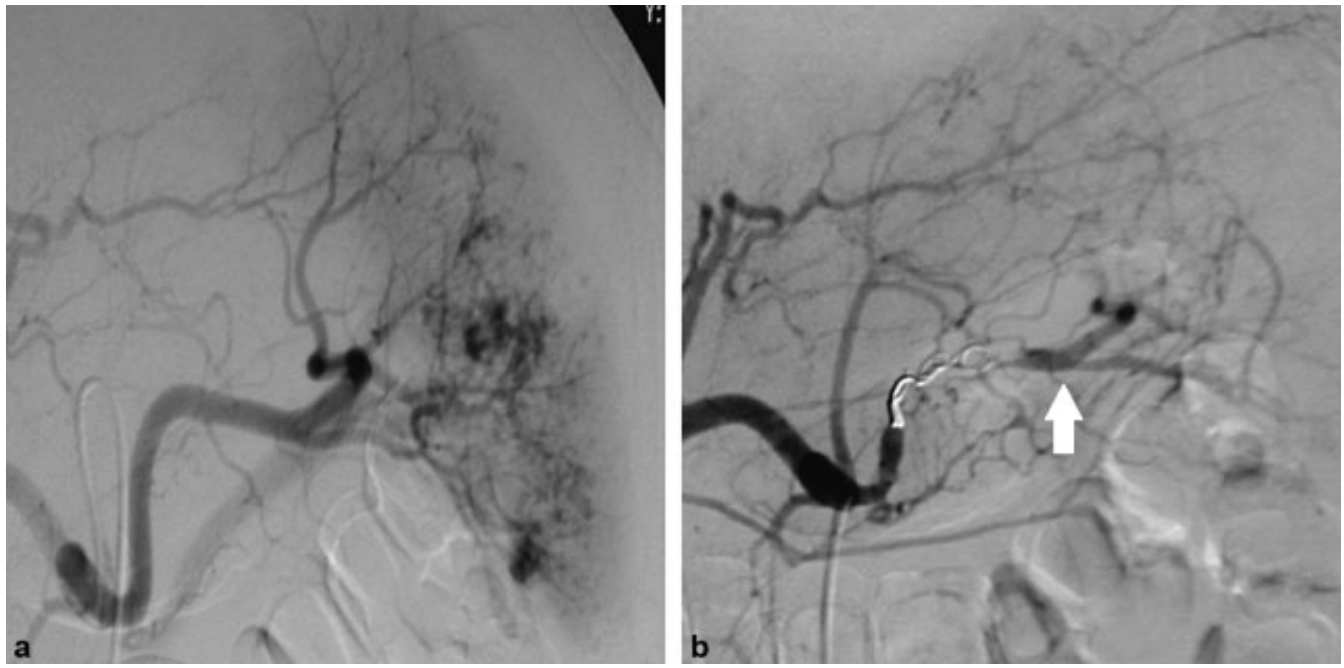

Fig. 16 (a) Digital subtraction angiography demonstrates multiple splenic injuries. (b) Proximal splenic artery embolization with coils performed; note distal recanalization of the splenic arteries (arrow) through collaterals.
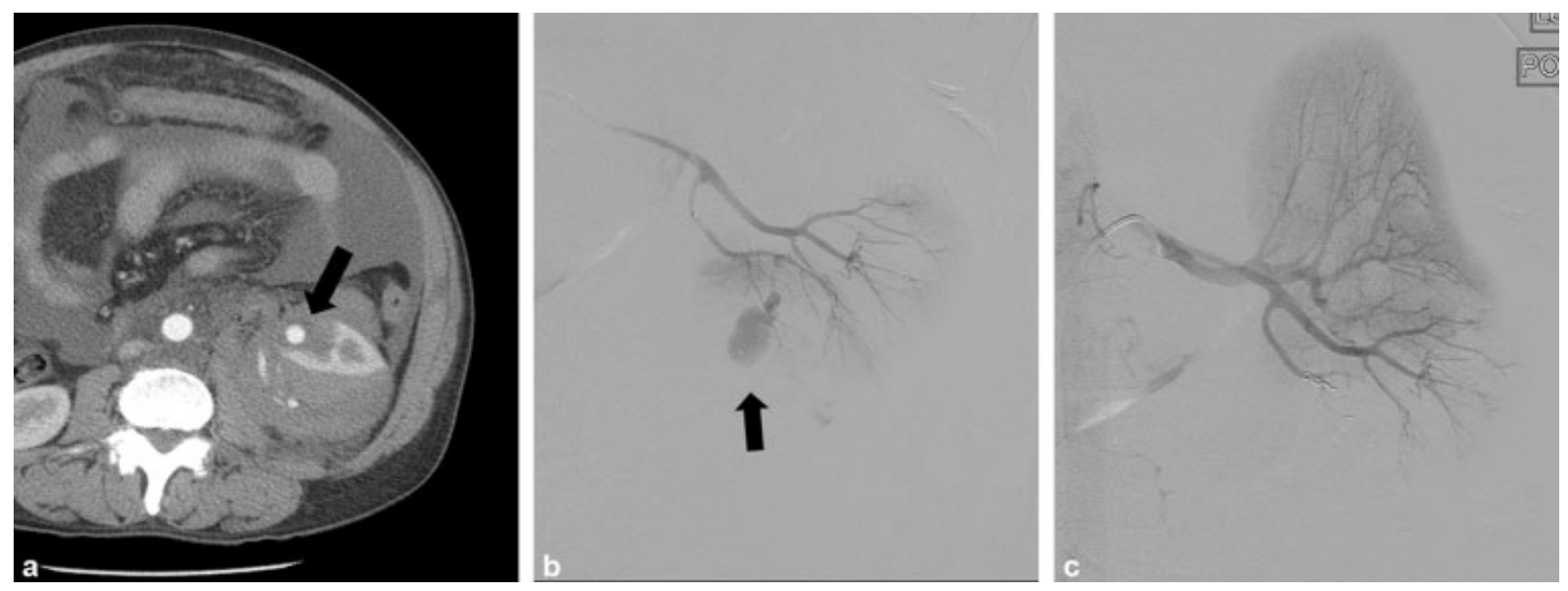

Fig. 17 Stab wound in the flank. CT shows perirenal hematoma with kidney pseudoaneurysm (PSA) (arrow) and active extravasation. (b) Digital subtraction angiography (DSA) shows PSA of the lower pole (arrow). (c) DSA after superselective coil embolization demonstrates no further extravasation.
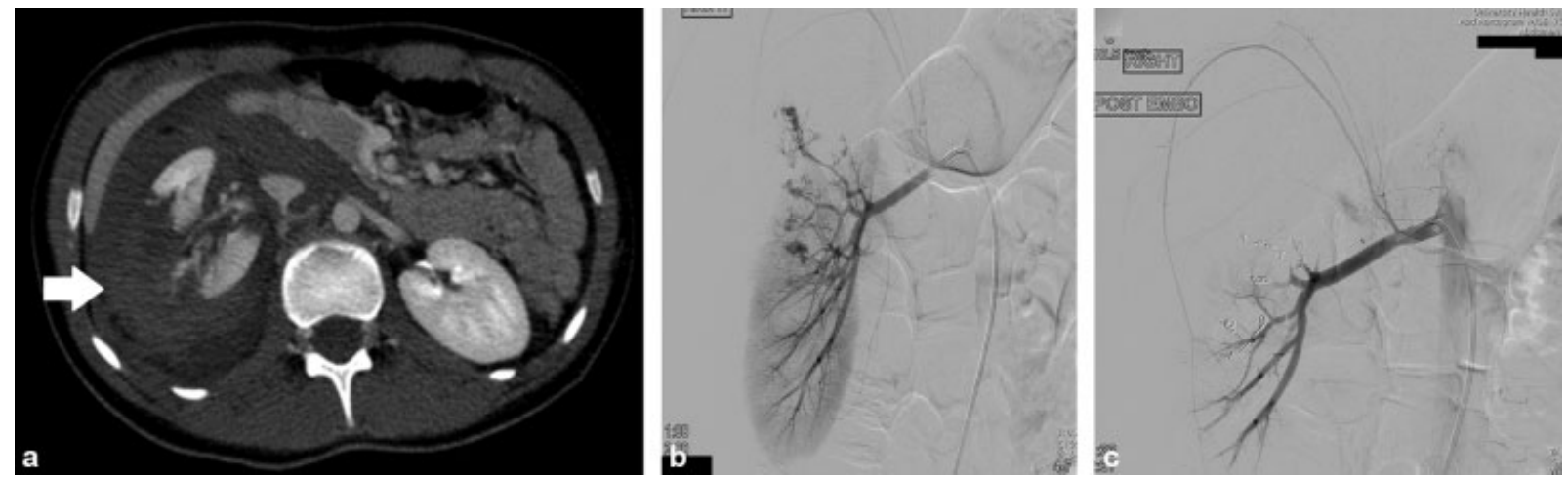

Fig. 18 (a) CT demonstrates a shattered right kidney with large perirenal hematoma (arrow). (b) Digital subtraction angiography (DSA) shows multiple areas of contrast extravasation in the mid and right upper pole. (c) After coil embolization of multiple branches, DSA shows preservation of vascular supply to the lower pole of the kidney. 

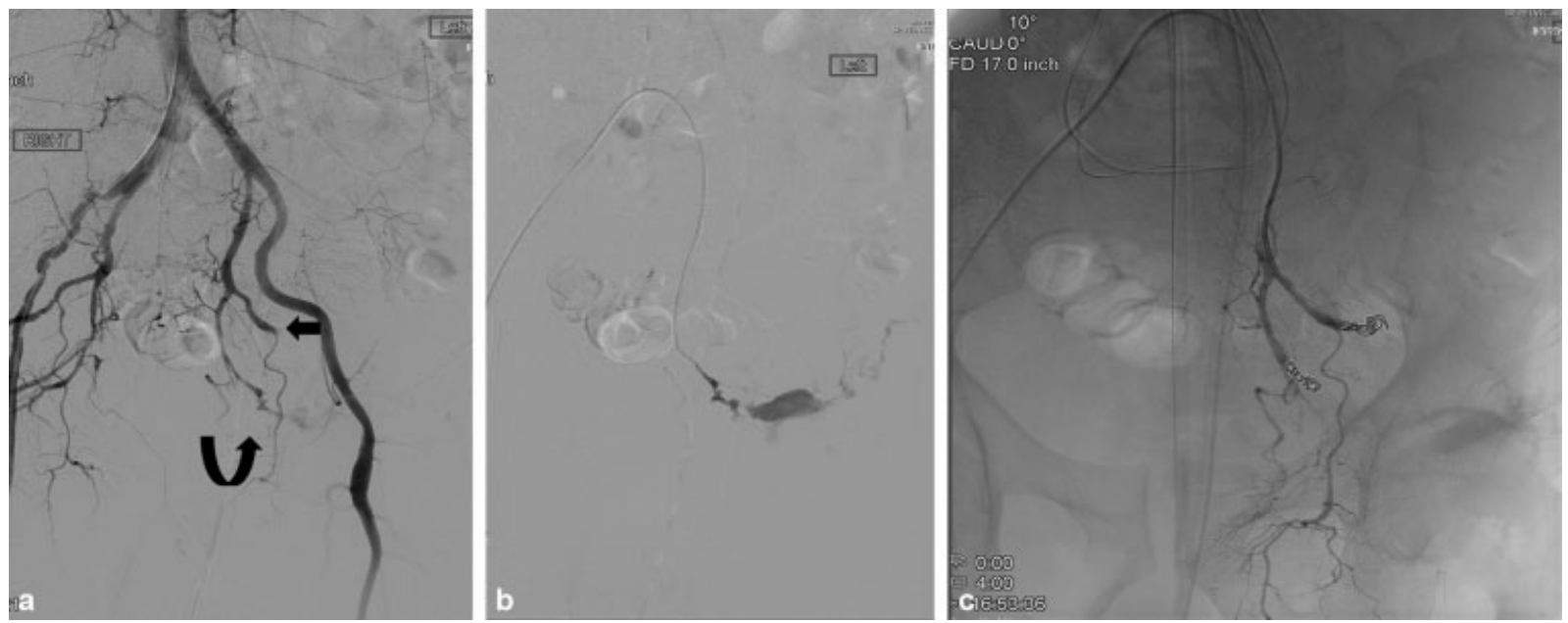

Fig. 19 Pelvic fractures with hypotension. (a) Nonselective pelvic angiography shows transection of the left superior gluteal (arrow) and active extravasation from the inferior left gluteal artery (curve arrow). (b) Selective angiography redemonstrating active extravasation from the left inferior gluteal artery. (c) Angiography after coil embolization of both gluteal arteries demonstrates no further contrast extravasation.

\section{Pelvis}

\section{Key Points}

Always selective angiograms of each hypogastric in various projections.

Extensive collateral circulation.

Embolization agents: coils, Gelfoam, glue.

Rebleeding from adjacent areas not uncommon.

Check the external iliac and femoral branches.

Retroperitoneal hemorrhage after pelvic fractures is difficult to control with surgery, and packing is often performed. Embolization is now the gold standard to control hemorrhage in unstable patients with pelvic fractures. ${ }^{7,8,35}$ Many of the pelvic bleeds are venous in origin; arterial bleeding is more commonly seen in patients with complex unstable pelvis fractures and those who are hemodynamically unstable and/or with positive CT findings. ${ }^{36} \mathrm{CT}$ areas of contrast extravasation or vessel transection are very useful to guide the procedures. Open book-type fractures are associated with bleeding from the posterior division of the hypogastric, mainly the superior gluteal artery and the lateral sacral artery (-Fig. 19). Lateral compression fractures correlate with hemorrhage from the anterior division, mainly the internal pudendal and the obturator artery ( - Fig. 20). ${ }^{37}$

Selective angiography with injection of each hypogastric artery is recommended. Checking the external iliac arteries and common femoral arteries is also important, as branches of the epigastric and circumflex iliac can also be injured and there are anatomic variants such as the origin of obturator artery from inferior epigastric or common femoral artery. Occasionally, the lumbar arteries are also injured.

Superselective embolization using Gelfoam or particles, or more commonly microcoils, is recommended. In patients who are hemodynamically unstable with multiple areas of contrast extravasation, nonselective proximal embolization of the anterior, posterior, or sometimes the hypogastric artery with Gelfoam can be a lifesaving procedure. ${ }^{35}$

The potential for distal bleeding from collateral circulation can be a significant problem ( - Fig. 13). The rebleeding rates are 0 to $20 \%$; repeat angiograms are recommended for patients who continue to require blood transfusions, are unstable, or had multiple bleedings areas in the initial angiography. ${ }^{9}$

Serious complications have been reported after pelvic embolization including uterine and bladder necrosis, paresis, buttock ischemia, and impotence. ${ }^{38}$
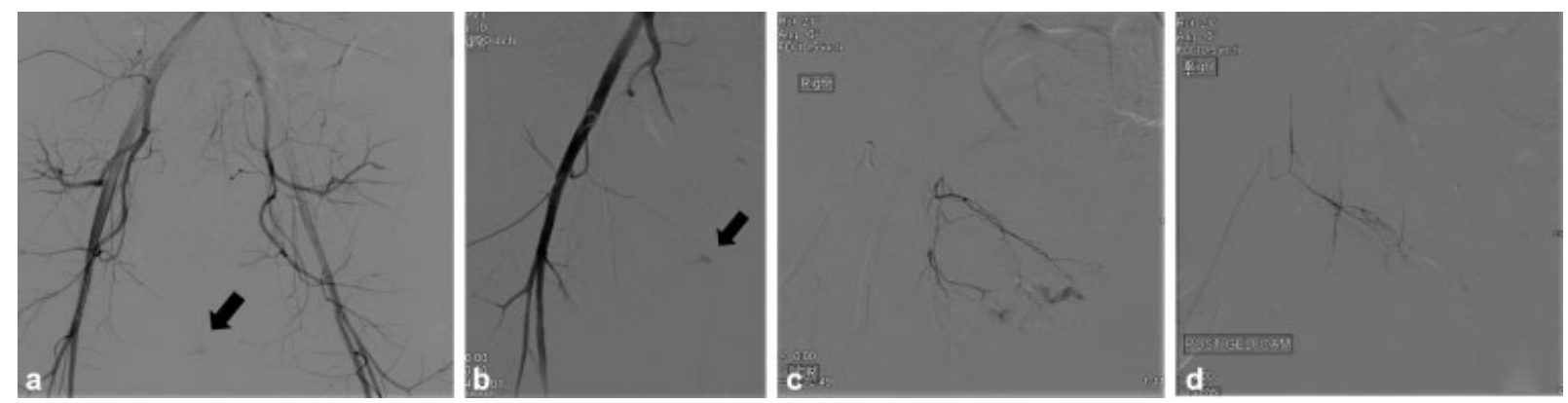

Fig. 20 Pelvic fracture with multiple associated injuries. (a) Nonselective pelvic angiography shows a faint amount of active extravasation near the pubis (arrow). (b) Hypogastric angiography was negative; however, the external iliac angiography shows injury in a pubic branch of the inferior epigastric artery (arrow). (c) Selective angiography with a microcatheter shows multiple areas of contrast extravasation. (d) Angiography after Gelfoam embolization demonstrates cessation of contrast extravasation. 


\section{Conclusion}

Transcatheter arterial embolization is a minimally invasive procedure that provides expedited and safe control of hemorrhage of traumatic injuries. Early embolization has proven to improve survival. A multidisciplinary approach with rapid response teams led by IR and trauma are critical part of the modern management of arterial injuries. Familiarization and adequate training with the use of the different embolization agents is very important to avoid major complications.

\section{Conflict of Interest}

None declared.

\section{References}

1 Wallis A, Kelly MD, Jones L. Angiography and embolisation for solid abdominal organ injury in adults - a current perspective. World J Emerg Surg 2010;5:18

2 Singh A, Kumar A, Kumar P, Kumar S, Gamanagatti S. "Beyond saving lives": current perspectives of interventional radiology in trauma. World J Radiol 2017;9(04):155-177

3 Ito K, Nagao T, Tsunoyama T, et al. Hybrid emergency room system improves timeliness of angioembolization for pelvic fracture. J Trauma Acute Care Surg 2020;88(02):314-319

4 Matsumoto J, Lohman BD, Morimoto K, Ichinose Y, Hattori T, Taira Y. Damage control interventional radiology (DCIR) in prompt and rapid endovascular strategies in trauma occasions (PRESTO): a new paradigm. Diagn Interv Imaging 2015;96(7-8):687-691

5 Spahn DR, Cerny V, Coats TJ, et al; Task Force for Advanced Bleeding Care in Trauma. Management of bleeding following major trauma: a European guideline. Crit Care 2007;11(01):R17

6 Jarvis S, Kelly M, Mains C, et al. A descriptive survey on the use of resuscitative endovascular balloon occlusion of the aorta (REBOA) for pelvic fractures at US level I trauma centers. Patient Saf Surg 2019; 13:43

7 Agolini SF, Shah K, Jaffe J, Newcomb J, Rhodes M, Reed JF III. Arterial embolization is a rapid and effective technique for controlling pelvic fracture hemorrhage. J Trauma 1997;43(03):395-399

8 Tanizaki S, Maeda S, Matano H, Sera M, Nagai H, Ishida H. Time to pelvic embolization for hemodynamically unstable pelvic fractures may affect the survival for delays up to $60 \mathrm{~min}$. Injury 2014; 45(04):738-741

9 Padia SA, Ingraham CR, Moriarty JM, et al. Society of Interventional Radiology Position Statement on endovascular intervention for trauma. J Vasc Interv Radiol 2020;31(03):363-369.e2

10 Lopera JE. Embolization in trauma: principles and techniques. Semin Intervent Radiol 2010;27(01):14-28

11 Jander HP, Russinovich NA. Transcatheter Gelfoam embolization in abdominal, retroperitoneal, and pelvic hemorrhage. Radiology 1980;136(02):337-344

12 Vaidya S, Tozer KR, Chen J. An overview of embolic agents. Semin Intervent Radiol 2008;25(03):204-215

13 Barth KH, Strandberg JD, White RI Jr. Long term follow-up of transcatheter embolization with autologous clot, Oxycel and Gelfoam in domestic swine. Invest Radiol 1977;12(03):273-280

14 Abada HT, Golzarian J. Gelatine sponge particles: handling characteristics for endovascular use. Tech Vasc Interv Radiol 2007;10 (04):257-260

15 Katsumori T, Kasahara T. The size of gelatin sponge particles: differences with preparation method. Cardiovasc Intervent Radiol 2006;29(06):1077-1083

16 Laurent A, Wassef M, Saint Maurice JP, et al. Arterial distribution of calibrated tris-acryl gelatin and polyvinyl alcohol microspheres in a sheep kidney model. Invest Radiol 2006;41(01):8-14
17 Lopera JE. The Amplatzer vascular plug: review of evolution and current applications. Semin Intervent Radiol 2015;32(04):356-369

18 Doody O, Given MF, Lyon SM. Extremities-indications and techniques for treatment of extremity vascular injuries. Injury 2008; 39(11):1295-1303

19 Johnson CA. Endovascular management of peripheral vascular trauma. Semin Intervent Radiol 2010;27(01):38-43

20 Lopera JE, Suri R, Cura M, Kroma G, El-Merhi F. Crural artery traumatic injuries: treatment with embolization. Cardiovasc Intervent Radiol 2008;31(03):550-557

21 MacGoey P, Navarro A, Beckingham IJ, Cameron IC, Brooks AJ. Selective non-operative management of penetrating liver injuries at a UK tertiary referral centre. Ann R Coll Surg Engl 2014;96(06): 423-426

22 Malhotra AK, Fabian TC, Croce MA, et al. Blunt hepatic injury: a paradigm shift from operative to nonoperative management in the 1990s. Ann Surg 2000;231(06):804-813

$23 \mathrm{Xu}$ J, Xie L, Sejian K, et al. Selective embolization of hepatic trauma reduces failure rate of nonoperative therapy. Inter Med J Exp Clin Res 2017;23:5522-5533

24 Green CS, Bulger EM, Kwan SW. Outcomes and complications of angioembolization for hepatic trauma: a systematic review of the literature. J Trauma Acute Care Surg 2016;80(03):529-537

25 Dabbs DN, Stein DM, Scalea TM. Major hepatic necrosis: a common complication after angioembolization for treatment of high-grade liver injuries. J Trauma 2009;66(03):621-627, discussion 627-629

26 Crichton JCI, Naidoo K, Yet B, Brundage SI, Perkins Z. The role of splenic angioembolization as an adjunct to nonoperative management of blunt splenic injuries: a systematic review and metaanalysis. J Trauma Acute Care Surg 2017;83(05):934-943

27 Guinto R, Greenberg P, Ahmed N. Emergency management of blunt splenic injury in hypotensive patients: total splenectomy versus splenic angioembolization. Am Surg 2020;86(06):690-694

$28 \mathrm{Wu}$ SC, Chen RJ, Yang AD, Tung CC, Lee KH. Complications associated with embolization in the treatment of blunt splenic injury. World J Surg 2008;32(03):476-482

29 Hamers RL, Van Den Berg FG, Groeneveld AB. Acute necrotizing pancreatitis following inadvertent extensive splenic artery embolisation for trauma. Br J Radiol 2009;82(973):e11-e14

30 Mingoli A, La Torre M, Migliori E, et al. Operative and nonoperative management for renal trauma: comparison of outcomes. A systematic review and meta-analysis. Ther Clin Risk Manag 2017; 13:1127-1138

31 Vozianov S, Sabadash M, Shulyak A. Experience of renal artery embolization in patients with blunt kidney trauma. Cent European J Urol 2015;68(04):471-477

32 Coccolini F, Moore EE, Kluger Y, et al; WSES-AAST Expert Panel. Kidney and uro-trauma: WSES-AAST guidelines. World J Emerg Surg 2019;14:54

33 Huber J, Pahernik S, Hallscheidt P, et al. Selective transarterial embolization for posttraumatic renal hemorrhage: a second try is worthwhile. J Urol 2011;185(05):1751-1755

34 Lopera JE, Suri R, Kroma G, Gadani S, Dolmatch B. Traumatic occlusion and dissection of the main renal artery: endovascular treatment. J Vasc Interv Radiol 2011;22(11):1570-1574

35 Velmahos GC, Chahwan S, Hanks SE, et al. Angiographic embolization of bilateral internal iliac arteries to control life-threatening hemorrhage after blunt trauma to the pelvis. Am Surg 2000;66 (09):858-862

36 Wijffels DJ, Verbeek DO, Ponsen KJ, Carel Goslings J, van Delden OM. Imaging and Endovascular Treatment of Bleeding Pelvic Fractures: Review Article. Cardiovasc Intervent Radiol 2019;42(01):10-18

37 Sheridan MK, Blackmore CC, Linnau KF, Hoffer EK, Lomoschitz F, Jurkovich GJ. Can CT predict the source of arterial hemorrhage in patients with pelvic fractures? Emerg Radiol 2002;9(04):188-194

38 Hare WS, Holland CJ. Paresis following internal iliac artery embolization. Radiology 1983;146(01):47-51 